\title{
Two New Genera and Species of Oligocene Spikefishes \\ (Tetraodontiformes: Triacanthodidae), \\ the First Fossils of the
}

Hollardiinae and Triacanthodinae 


\title{
SERIES PUBLICATIONS OF THE SMITHSONIAN INSTITUTION
}

Emphasis upon publication as a means of "diffusing knowledge" was expressed by the first Secretary of the Smithsonian. In his formal plan for the institution, Joseph Henry outlined a program that included the following statement: "It is proposed to publish a series of reports, giving an account of the new discoveries in science, and of the changes made from year to year in all branches of knowledge." This theme of basic research has been adhered to through the years by thousands of titles issued in series publications under the Smithsonian imprint, commencing with Smithsonian Contributions to Knowledge in 1848 and continuing with the following active series:

\author{
Smithsonian Contributions to Anthropology \\ Smithsonian Contributions to Botany \\ Smithsonian Contributions to the Earth Sciences \\ Smithsonian Contributions to the Marine Sciences \\ Smithsonian Contributions to Paleobiology \\ Smithsonian Contributions to Zoology \\ Smithsonian Folklife Studies \\ Smithsonian Studies in Air and Space \\ Smithsonian Studies in History and Technology
}

In these series, the Institution publishes small papers and full-scale monographs that report the research and collections of its various museums and bureaux or of professional colleagues in the world of science and scholarship. The publications are distributed by mailing lists to libranies, universities, and similar instilutions throughout the world.

Papers or monographs submitted for series publication are received by the Smithsonian Institution Press, subject to its own review for format and style, only through departments of the various Smithsonian museums or bureaux, where the manuscripts are given substantive review. Press requirements for manuscript and art preparation are outlined on the inside back cover.

Robert McC. Adams

Secretary

Smithsonian Institution 


\title{
Two New Genera and Species of Oligocene Spikefishes (Tetraodontiformes: Triacanthodidae), the First Fossils of the
} Hollardiinae and Triacanthodinae

\author{
James C. Tyler, Anna Jerzmańska, Alexandre F. Bannikov, \\ and Jacek Świdnicki
}

MITHSONIAN INSTITUTION PRESS

Washington, D.C. 


\section{A B S T R A C T}

Tyler, James C., Anna Jerzmańska, Alexandre F. Bannikov, and Jacek Świdnicki. Two New Genera and Species of Oligocene Spikefishes (Tetraodontiformes: Triacanthodidae), the First Fossils of the Hollardiinae and Triacanthodinae. Smithsonian Contributions to Paleobiology, number 75, 27 pages, 20 figures, 3 tables, 1993.- - Two new genera and species of spikefishes from the Menilitic Formation (late Tethys Sea) of the Upper Oligocene of Poland represent the first fossils of the two subfamilies of the tetraodontiform family Triacanthodidae. One of the new genera, Prohollardia, has a dome-like supraoccipital, the epiotics separated medially on the dorsal surface of the skull, the epiotics articulated anteriorly with the frontals, and a shaft-like posterior process of the pelvis, which are diagnostic features of the Hollardiinae. The other, Carpathospinosus, has a flattened supraoccipital with only a small crest anteromedially, the epiotics in contact medially on the dorsal surface of the skull, the epiotics separated from the frontals by the sphenotic, and a broad basin-like posterior process of the pelvis, which are diagnostic features of the Triacanthodinae. Some of these features of the Triacanthodinae are shown to be derived.

The separation of the two subfamilies of Triacanthodidae took place no less than about 29 to 24 MYA.

In an addendum, the Oligocene fish from Romania that was described in the dactylopteriform family Cephalacanthidae (Dactylopteridae) as Cephalacanthus trispinosus Ciobanu (1977) is referred to the Triacanthidae (the anatomically derived sistergroup of the Triacanthodidae) as a member of the triplespine genus Acanthopleurus Agassiz (1842). The single specimen is a juvenile and at least closely related to A. serratus Agassiz (1842) and A. collettei Tyler (1980), both from the Oligocene of Switzerland, and possibly identical to one or the other.

OFFICIAL PUBLICATION DATE is handstamped in a limited number of initial copies and is recorded in the Institution's annual report, Smithsonian Year. SERIES COVER DESIGN: The trilobite Phacops rana Green.

\footnotetext{
Library of Congress Cataloging-in-Publication Data

Tyler, James $C$.

Two new genera and species of Oligocene spikefishes (Tetraodontiformes: Triacanthodidae), the first fossils of the Hollardiinae and Triacanthodinae / James C. Tyler...[et al.].

p. cm. - (Smithsonian contributions to paleobiology ; no. 75)

Includes bibliographical references.

1. Prohollardia avita-Poland. 2. Carpathospinus propheticus-Poland. 3. Paleontology-Oligocene. 4. Paleontology-Poland. I. Tyler, James C., 1935- II. Series. QE701.S56 no. 75 [QE852.T48] $560 \mathrm{~s}-\mathrm{dc} 20$ [567'.5] 93-672
}

( The paper used in this publication meets the minimum requirements of the American National Standard for Permanence of Paper for Printed Library Materials Z39.48-1984. 


\section{Contents}

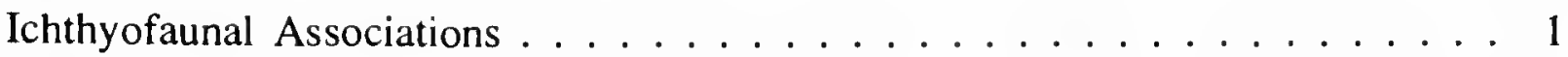

Methods and Documentation of Outgroup Data . . . . . . . . . . . . . 2

Acknowledgments ..................... 2

Order Tetraodontiformes Berg (1940) . . . . . . . . . . . . . 3

Family TRIACANTHODIDAE sensu Tyler $(1980) \ldots \ldots \ldots \ldots \ldots$

Subfamily Hollardinae Tyler $(1968) \ldots \ldots \ldots \ldots$

Prohollardia, new genus .................. 3

Diagnosis ...................... 3

Prohollardia avita, new species ............... 3

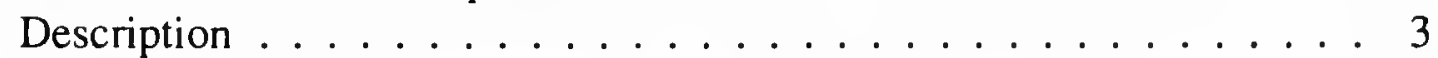

Head ..................... 3

Vertebral Column ................. 8

Pectoral Fin and Girdle . . . . . . . . . . . . 8

Pelvic Fin and Girdle . . . . . . . . . . . . . . 8

Spiny Dorsal Fin . . . . . . . . . . . . . . . . . . 9

Soft Dorsal Fin . . . . . . . . . . . . . . 10

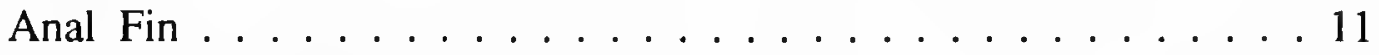

Caudal Fin and Skeleton . . . . . . . . . . . . 11

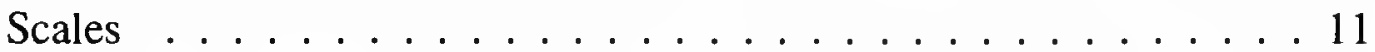

Subfamily TRIACANTHODINAE Tyler $(1968) \ldots \ldots \ldots \ldots \ldots \ldots$

Carpathospinosus, new genus . . . . . . . . . . . . . . 11

Diagnosis .......................... 11

Carpathospinosus propheticus, new species . . . . . . . . . . 12

Description . . . . . . . . . . . . . . . 12

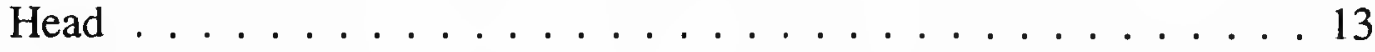

Vertebral Column ................... . . . . . .

Pectoral Fin and Girdle. . . . . . . . . . . . . . 14

Pelvic Fin and Girdle . . . . . . . . . . . . . . . 14

Spiny Dorsal Fin . . . . . . . . . . . . . . . . . 16

Soft Dorsal Fin . . . . . . . . . . . . . . . 17

Anal Fin . . . . . . . . . . . . . . . . 17

Caudal Fin and Skeleton . . . . . . . . . . . . . . 17

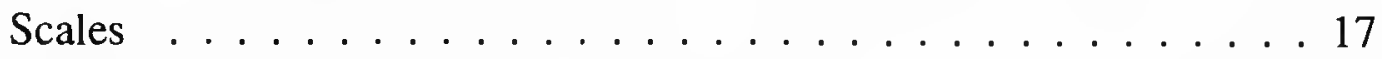

Other Relevant Fossil Taxa . . . . . . . . . . . . . . . . . . . . 17

Discussion of Subfamilial Defining Characters ............ 18

Pelvis . . . . . . . . . . . . . . . . . . . 21

Position of Epiotics on Dorsal Surface of Skull . . . . . . . . . . . . . 22

Epiotic Anterior Articulation . . . . . . . . . . . . . . . . 22

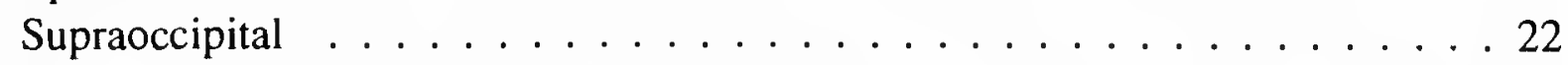

First Basal Pterygiophore of Anal Fin . . . . . . . . . . . . . . . 23

Summary of Subfamilial Characters of New Taxa . . . . . . . . . . . . 23

Relationships of Prohollardia in Hollardiinae . . . . . . . . . . . . . . 23

Synapomorphies of Prohollardia and Hollardia . . . . . . . . . . . . . . 24

Similarities between Prohollardia and Other Genera . . . . . . . . . . . . . . 24

Summary of Relationships of Prohollardia . . . . . . . . . . . . . . 25 
Relationships of Carpathospinosus in Triacanthodinae . . . . . . . . . 25

Referral of Cephalacanthus trispinosus Ciobanu to Triacanthidae . . . . . . 25

Conclusion . . . . . . . . . . . . . . . . . . . 26

Literature Cited . . . . . . . . . . . . . . . . . . 27 


\title{
Two New Genera and Species of Oligocene Spikefishes (Tetraodontiformes: Triacanthodidae), the First Fossils of the Hollardiinae and Triacanthodinae
}

\author{
James C. Tyler, Anna Jerzmańska, Alexandre F. Bannikov, \\ and Jacek Świdnicki
}

\section{Introduction}

Continuing annual explorations since 1954 by the Department of Paleozoology of Wrocław University to document the Oligocene ichthyofauna of the portion of the Carpathian Mountains in southern Poland have obtained thousands of specimens of marine fishes within the Menilitic Formation (Menilite Beds) of the late Tethys Sea. These collections contain fishes from all six IPM (Ichthyofauna, Paleogene, Menilite) zones (Kotlarczyk and Jerzmańska, 1976). The zones range in age from about 36 MYA for the beginning of IPM 1 to about 24 MYA for the end of IPM 6 (Kotlarczyk and Jerzmańska, 1988), and in habitat from epi- through meso- to bathypelagic and benthic to neritic (Jerzmańska and Kotlarczyk, 1976).

Some of these specimens are the first fossil records for families otherwise known only from Recent species (such as Alepocephalidae; Jerzmańska, 1979). Many of them are judged to be anatomically distinctive at the generic level from their Recent relatives (Jerzmańska, 1968, 1974), such as the two new genera of triacanthodids described herein. Others are only specifically distinct (such as the caproids Capros radobojanus (Kramberger) and C. medianus Swidnicki and the zeid Zenopsis clarus Daniltshenko), while some appear to be identical with Recent species (such as the zeid Zeus faber Linnaeus) (Świdnicki, 1986).

James C. Tyler, Office of the Director, National Museum of Natural History, Smithsonian Institution, Washington, D.C. 20560. Anna Jerzmańska and Jacek Świdnicki, Zoological Institute, Wroctaw University, Sienkiewicza 21, 50-335 Wroctaw, Poland. Alexandre F. Bannikov, Paleontological Institute, Russian Academy of Sciences, Profsoyuznaya 123, 117647 Moscow, Russia.
Among the materials collected between 1981-1990 at Błażowa in IPM 6 (range about 27-24 MYA) and in 1983-1987 at Przysietnica in IPM 4 (range about 29-28 MYA) are specimens of two new genera and species of spikefishes that are the first fossil records of the triacanthodid subfamilies Hollardiinae and Triacanthodinae. The descriptions of the hollardiin Prohollardia avita, new genus and species, and the triacanthodin Carpathospinosus propheticus, new genus and species, are based on well-preserved and complete holotypes and, respectively, three and nine paratypes. Although the paratypes are not as well preserved overall as the holotypes, they have certain anatomical features well exposed and have substantially expanded our knowledge of the new taxa.

These two new taxa of the Triacanthodidae are especially interesting systematically because they represent both of the subfamilies of triacanthodids, which until now were known only from Recent species. This establishes that the division of the family into two subfamilial linages (the Hollardiinae with Prohollardia and two Recent genera, and the Triacanthodinae with Carpathospinosus and nine Recent genera) took place no less than about 29 to 24 MYA.

\section{ICHTHYOFAUNAL ASSOCIATIONS}

In five of the six IPM zones the predominant fishes are mesopelagic, with a lesser number of epipelagic and benthic forms, whereas IPM 2 contains only neritic and sublittoral species. IPM zones 6 and 4 in which Prohollardia and Carpathospinosus have been found, respectively, are both dominated by mesopelagic fishes such as the myctophid Eomyctophum, the photichthyid Vinciguerria, and the ster- 
noptychids Polyipnus (IPM 4 only) and Argyropelecus (IPM 6 only). Less frequent are the epipelagic clupeids Alosa and Clupea, the trichiurid Lepidopus, and the scombrid Scomber (IPM 6 only). Least common in zones 4 and 6 are benthic species such as Pleuronectiformes (genera undetermined), the caproid Capros, and the zeid Zeus (for the biostratigraphy of the Menilite Beds see Kotlarczyk and Jerzmańska, 1976, 1988; Jerzmańska and Kotlarczyk, 1981).

The two new genera of Triacanthodidae significantly increase the known benthic component of zones IPM 4 and 6 because they presumably were bottom dwelling like Recent triacanthodids, which occur benthically at depths of 38 to over $900 \mathrm{~m}$ (usually 180 to $500 \mathrm{~m}$ ), with one specialized bathypelagic species found at over $1000 \mathrm{~m}$ depth (Tyler, 1968:62, 174). The smallest specimens of one of the new species, Carpathospinosus propheticus, are 12-18 mm SL and could be either epipelagic postlarval stages or recently settled benthic juveniles.

\section{Methods and Documentation OF OUTGRoup Data}

Standard length (SL) is from the tip of the upper jaw to the end of the hypural plate. Most measurements of the fossils are given with confidence to the nearest $0.1 \mathrm{~mm}$, but those of which we are less sure are given as "about" or, with the least precision, "estimated." Drawings were prepared with the use of a camera lucida on a Olympus stereomicroscope.

Measurement definitions, bone terminology, and comparative data for the Recent species follow Tyler (1968). Of particular interest here is the process of the pelvis behind the bases of the pelvic spines (posterior process). Its length is measured along the midline from the level of the middle of the bases of the spines to the distal end of the pelvis; its width is measured across both halves of the pelvis between the locking flanges of the pelvic spines (estimated if necessary in the fossils). In text discussions of the pelvis, the term "process" when unmodified refers to the posterior process and not to the ascending process. In the fossil specimens, head length is from the tip of the upper jaw to the place estimated to be the upper end of the gill opening between the anterior edge of the cleithrum and the posterior edge of the opercle.

Abbreviations for the names of bones in the illustrations are: Art $=$ articular; $\mathrm{Bpt}=$ basal pterygiophore; $\mathrm{Br}=$ branchiostegal ray; Chy = ceratohyal; $\mathrm{Cl}=$ cleithrum; Den = dentary; $\mathrm{Ecp}=$ ectopterygoid; Ep = epiotic; Epu = epural; Eth = ethmoid; Fr = frontal; Hhy = dorsal and ventral hypohyals; Hyo = hyomandibula; Hyp = hypurals; Iop = interopercle; $\mathrm{Mpt}=$ metapterygoid; $\mathrm{Msp}=$ mesopterygoid $\mathbf{M x}=$ maxilla; $\mathrm{Ns}=$ neural spine; $\mathrm{Op}=$ opercle; $\mathrm{Pal}=$ palatine; $\mathrm{Pas}=$ parasphenoid $\mathrm{Pcl}=$ postcleithrum; Pel = pelvis; $\mathrm{Pf}=$ prefrontal (lateral ethmoid); Phyp = parhypural; Pmx = premaxilla; $P$ op $=$ preopercle; $P$ Pot $=$ prootic; Ptot = pterotic $;$ Pts = pterosphenoid $; \mathrm{Ptt}=$ posttemporal $; \mathrm{Pu}=$ preural centra; $\mathrm{Qu}=$ quadrate; $\mathrm{Scl}=$ supracleithrum; $\mathrm{Soc}=$ supraoccipital; Sop = subopercle; Sph = sphenotic; $\mathrm{Sym}=$ symplectic; $\mathrm{Uh}=$ urohyal; $\mathrm{V}=$ vomer.
Documentation of the osteological features of tetraodontiform outgroups is from Tyler $(1968,1980)$. Data on the osteology of caproids and zeiforms are from the descriptions of Zeus by Starks (1898), Norman (1934), and Gregory (1933); the description of Grammicolepis by Shufeldt (1888); the comparisons between the Upper Cretaceous Palaeocyttus and the Recent Cyttus, Neocyttus, and Zeus by Gaudant (1978); the comparisons between the Oligocene Zeus faber and the Recent Zeus and Zenopsis by Świdnicki (1986); the comparisons between caproids and zeiforms by Gaudant (1977), Rosen (1984), and Zehren (1987); the review of zeiform characteristics by Heemstra (1980); and the works on fossil caproids by Sorbini (1983), Sorbini and Bottura (1987), Świdnicki (1988), and Bannikov (1991). We believe the upper Cretaceous specimen described by Gayet (1980a,b) as Microcapros to be a beryciform (Bannikov, 1991:55).

We examined cleared and stained specimens at the National Museum of Natural History and dry skeletal materials at the American Museum of Natural History of the zeids Zeus, Zenopsis, Capromimus, Cyttus, Cyttopsis, and Stethopristes, the macrurocyttid Zenion, the grammicolepidids Grammicolepis and Xenolepidichthys, the parazenid Parazen, the oreosomatids Neocyttus, Allocyttus, and Pseudocyttus, and the caproids Capros and Antigonia. Additionally, Steven Zehren has provided us data on zeiform osteology used for outgroup analysis in his study of caproids.

The familial relationships of the Tetraodontiformes adopted here are essentially those determined by Winterbottom's (1974) phylogenetic analysis, as modified for fossil groups by Tyler and Bannikov (1992).

Abbreviations used in parenthetical expressions identifying outgroups in the text are: 1 o.g. and 2 o.g. for the first and second successive outgroups.

\section{ACKNOWLEDGMENTS}

We appreciate the support provided by the Polish Academy of Sciences and Wroclaw University for travel accommodations for the participants from Russia and the United States that facilitated the research with their Polish colleagues. Ewa Swidnicka of the Department of Paleozoology, Wrocław University, greatly assisted the research during the entire study. Steven Zehren, University of Alabama, generously provided us with literature and osteological data on zeiforms. Hans-Dieter Sues, Royal Ontario Museum, Toronto, carefully searched the collections at the Institut für Palaeontologie, Bonn, for specimens of Cryptobalistes and prepared one of those he found to enhance its exposure. Richard Vari, Smithsonian Institution, spent much time giving us good advice on our cladistic analyses, and the manuscript greatly benefited from his constructive suggestions and from those of Richard Winterbottom, Royal Ontario Museum, Toronto, and C.L. Smith, American Museum of Natural History, New York, elicited during the preacceptance review process. At the Smithsonian Institution Press we thank Craig Warren for the 
careful copy editing and typesetting of the paper and Diane M. Tyler for the preparation of the tables.

This research was supported in part by Polish grant CPBP 04.03.III/5.3 to A. Jerzmańska.

\section{Order TETRAODONTIFORMES Berg (1940)}

\section{Family TRIACANTHODIDAE sensu Tyler (1980)}

\section{Subfamily HollardinaE Tyler (1968)}

This subfamily includes five species in the Recent genera Hollardia and Parahollardia of the western Atlantic and central Pacific oceans and the new Oligocene genus Prohollardia from the Polish Carpathian Mountains.

Prohollardia has a dome-like supraoccipital with a convex posterior surface, the epiotics separated from one another medially on the dorsal surface of the skull, the epiotics articulated anteriorly with the frontals, and a shaft-like posterior process of the pelvis. These are diagnostic characteristics of the subfamily Hollardiinae. While these features are used to define the subfamily, our analysis indicates that none of them are unequivocally derived and consequently we cannot demonstrate that the Hollardiinae is monophyletic (see "Discussion of Subfamilial Defining Characters").

\section{Prohollardia, new genus}

TYPE SPECIES.-Prohollardia avita, new species, by monotypy and present designation.

ETYMOLOGY.-From the Greek, pro (early or ancestral) plus hollardia, for both the subfamily Hollardiinae of which the new genus is the earliest known member and its proposed sistergroup relationship with Hollardia Poey (1861). That name honors Henri Hollard, the pioneer mid-19th century monographer of the anatomy and classification of the plectognath (tetraodontiform) fishes; feminine.

\section{DIAGNOSIS}

Prohollardia differs from all other Triacanthodidae by the presence of an enlarged scale plate with a prominent thorn-like spine projecting dorsally over each eye (versus no such scale); the almost vertical orientation of the hyomandibula (versus oriented obliquely anteroventrally); the last basal pterygiophore of the spiny dorsal fin and the first two basal pterygiophores of the soft dorsal fin oriented approximately vertically (versus inclined anteroventrally); the spiny dorsal-fin base slightly shorter than the soft dorsal-fin base (versus spiny dorsal-fin base significantly longer than soft dorsal-fin base); a longer soft dorsal-fin base, higher soft dorsal fin, longer head, and more extensive covering of the spiny dorsal fin and its membranes by spinulose scales.

Prohollardia differs from all other Hollardiinae by the more pronounced difference in the relative lengths of the first and second dorsal spines; the more pronounced difference in the relative lengths of the pelvic spine and posterior process of the pelvis; and the more anterior origin of the spiny dorsal fin in relation to the gill opening (see description for quantification of these diagnostic features).

\section{Prohollardia avita, new species}

FIGURES 1-10; TABLE 1

MATERIAL.-Holotype, Zoological Institute, Department of Paleozoology, Wrocław University (ZPALWr.) A/2096, an almost complete specimen in part and counterpart, except for the posterior part of the caudal fin and the anterior part of the anal fin, $44.4 \mathrm{~mm}$ SL. Three paratypes: ZPALWr. A/2097, in part and partial counterpart, estimated $25.0 \mathrm{~mm}$ SL; ZPALWr. A/2098, in part and counterpart, about $29.0 \mathrm{~mm} \mathrm{SL}$; ZPALWr. A/2099, single plate, about $26.0 \mathrm{~mm} \mathrm{SL}$. All of the materials are impressions in siliceous-argillaceous shales from the same horizon and locality, see below.

TYPE HORIZON.-Upper Oligocene, zone IPM 6 of the Menilite Beds.

TyPE LOCaliTY.-Błażowa, south of Rzeszów, Rzeszów Province, the Carpathians, southeast Poland $\left(49^{\circ} 53^{\prime} \mathrm{N}\right.$, $22^{\circ} 06^{\prime} \mathrm{E}$ ).

DIAGNOSIS.-As for the genus.

ETYMOLOGY.-From the Latin avitus (very old or ancient), in reference to the Oligocene age of the type material; feminine.

\section{DESCRIPTION}

Judging from the body sizes of the various life history stages of the Recent species of the family, the holotype (Figures 1,2) is probably a young adult and the paratypes are probably juveniles. Measurements for the specimens are given in Table 1. A summary of the differences between Prohollardia, Carpathospinosus, and the Recent genera of the two subfamilies is given in Table 3.

The maximum proportional depth of the body is relatively great in Prohollardia, 70.0\%-72.0\% SL (average 71.2), compared to other triacanthodids, although, like allometry in head size discussed below, this is at least partially a function of the small size of the type specimens. The only other triacanthodids with comparably great body depths at this size are hollardiins: two of the three species of the Recent Hollardia, $H$. meadi Tyler and $H$. hollardi Poey and one of the two species of the Recent Parahollardia, P. lineata (Longley), in which the depth is $65 \%-73 \%$ SL at about $30-50 \mathrm{~mm}$ SL. Among triacanthodins body depths as great as even about $57 \%-67 \%$ SL at small specimen sizes are found only in Johnsonina eriomma Myers.

HEAD. - The head (Figure 3 ) is exceptionally long (48.0\%$52.4 \% \mathrm{SL}$, average 49.5 ). In other triacanthodids the head is $33 \%-45 \%$ SL (longest in juveniles), with average values of $35 \%-40 \%$ SL in all Recent species with head shapes comparable to that of the new species (the notably elongate 


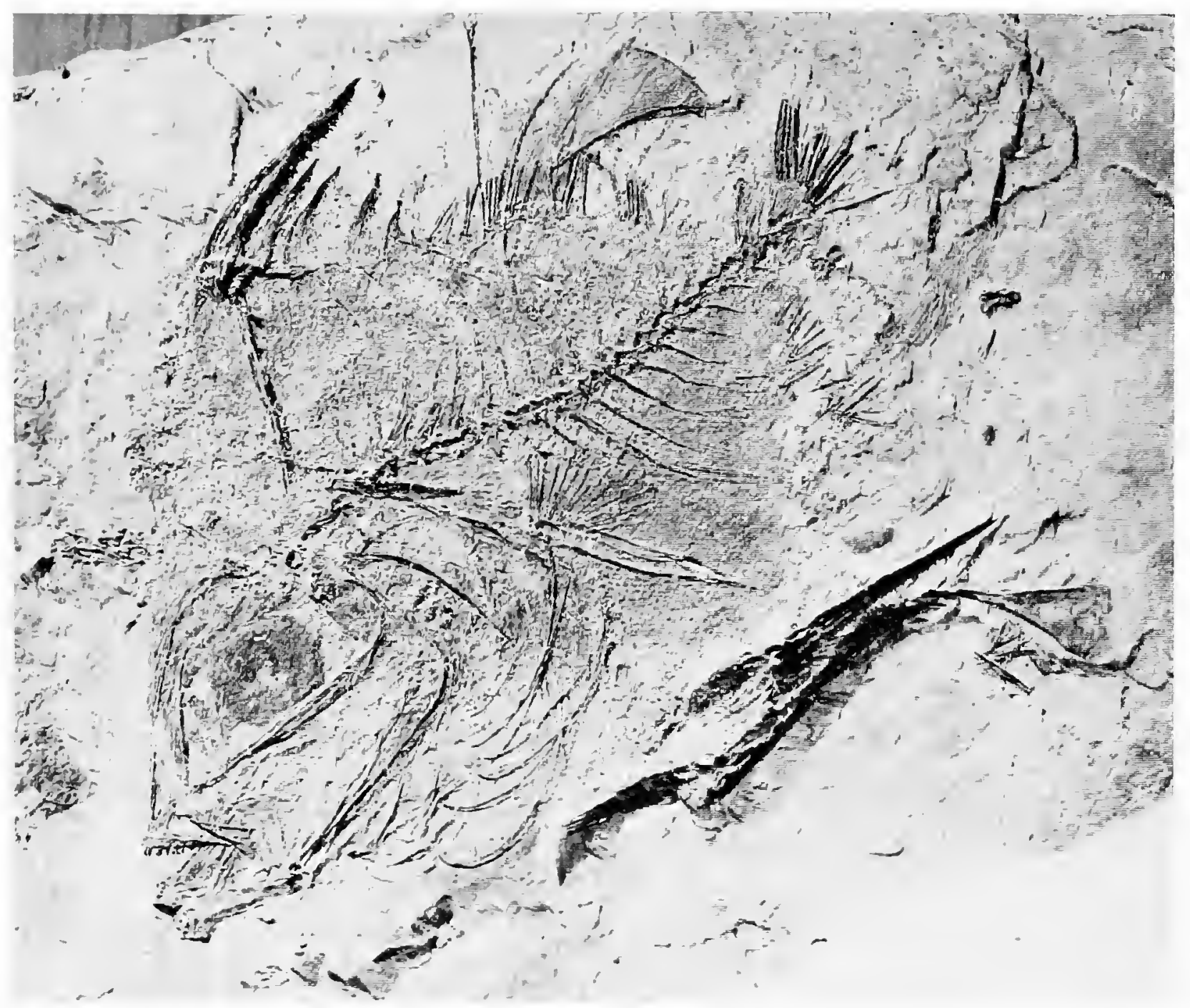

FIGURE 1.-Prohollardia avita, new genus and species, photograph of holotype, ZPALWr. A/2096, $44.4 \mathrm{~mm}$ SL, Menilite Beds, IPM 6, Błazowa, southern Poland, Carpathian Mountains, Upper Oligocene.

TABLE 1.-Measurements of Prohollardia avita, new genus and species.

\begin{tabular}{|c|c|c|c|c|c|c|c|c|}
\hline \multirow{3}{*}{ Character } & \multirow{2}{*}{\multicolumn{2}{|c|}{$\frac{\text { Holotype }}{\text { ZPALWr.A/2096 }}$}} & \multicolumn{6}{|c|}{ Paratypes } \\
\hline & & & \multicolumn{2}{|c|}{ ZPALWr.A/2099 } & \multicolumn{2}{|c|}{ ZPALWr.A/2097 } & \multicolumn{2}{|c|}{ ZPALWr.A/2098 } \\
\hline & $\mathrm{mm}$ & $\% \mathrm{SL}$ & $\mathrm{mm}$ & $\%$ SL & $\mathrm{mm}$ & $\%$ SL & $\mathrm{mm}$ & $\%$ SL \\
\hline Standard length & 44.4 & & $26.0^{*}$ & & $25.0 \dagger$ & - & $29.0^{*}$ & - \\
\hline Head length & 22.0 & 49.5 & $12.5 *$ & $48.0^{*}$ & $12.0 \dagger$ & $48.0^{\dagger}$ & $15.2^{*}$ & $52.4^{*}$ \\
\hline Body depth & $32.0^{*}$ & $72.0^{*}$ & $18.5^{*}$ & $71.5^{*}$ & $17.5 \dagger$ & $70.0 \dagger$ & & \\
\hline Predorsal length & 27.0 & 60.0 & 14.5 & $55.7^{*}$ & $14.2^{*}$ & $56.8 \dagger$ & & \\
\hline First dorsal spine & 12.5 & 28.1 & 5.4 & $20.7^{*}$ & 6.1 & $24.4 \dagger$ & & \\
\hline Second dorsal spine & 6.3 & 14.1 & 3.4 & $13.0^{*}$ & 3.3 & $13.2 \dagger$ & - & - \\
\hline Third dorsal spine & 5.6 & 12.6 & 2.2 & $8.4^{*}$ & 3.0 & $12.0 \dagger$ & - & - \\
\hline Pelvic spine & 13.4 & 30.1 & & & - & & 5.5 & $19.0 *$ \\
\hline Pelvis width & $3.0^{*}$ & $6.7^{*}$ & & - & - & & - & - \\
\hline Pelvis length & 9.5 & 21.4 & & - & - & & 4.2 & $14.5^{*}$ \\
\hline Spiny-dorsal base & $10.5^{*}$ & $23.6^{*}$ & $5.0^{*}$ & $19.2^{*}$ & - & & - & - \\
\hline Soft-dorsal base & 11.6 & 26.1 & $6.0^{*}$ & $23.0^{*}$ & - & & - & - \\
\hline Anal base & 8.2 & 18.0 & $4.3^{*}$ & $16.5^{*}$ & - & & & \\
\hline Soft-dorsal height & 10.2 & 23.0 & & - & - & & & \\
\hline
\end{tabular}

*Value is approximate.

$\nmid$ Value is an estimate (less precise than approximate). 


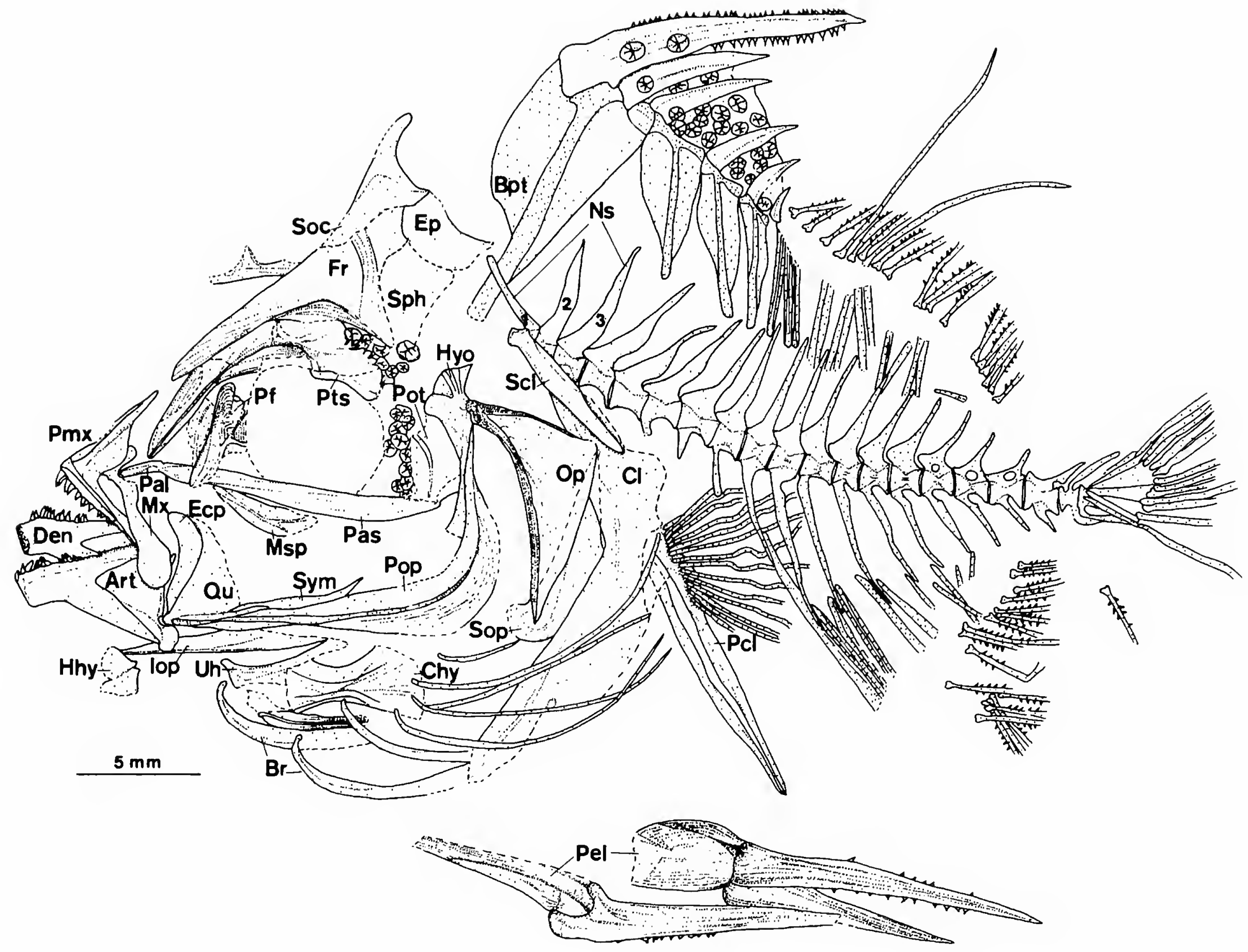

FIGURE 2.-Prohollardia avita, new genus and species, reconstruction based on holotype.

tubular snout in two highly specialized genera, Halimochirurgus and Macrorhamphosodes, results in head lengths of $50 \%-62 \% \mathrm{SL}$ ). The relative head size of the type materials of Prohollardia is significantly longer, even in comparison to head size in equally small specimens of Recent triacanthodids. The head in the other new Oligocene genus, Carpathospinosus, also is relatively long, $45.5 \% \mathrm{SL}$, somewhat shorter than in Prohollardia but only slightly longer than in small specimens of some other species of triacanthodids.

The supraoccipital (Figures 2,3) is entirely dome-like, as in other hollardiins, with a concave posterior profile in lateral view and what would be a convex or rounded posterior surface in posterior view. The supraoccipital articulates anteriorly with the posterior part of the frontals and laterally with the epiotics, separating the epiotics on the dorsal surface of the skull. The epiotics articulate anteriorly with the frontals. There are traces of the sphenotic below the posterior region of the frontal and anterior to the epiotic. The long frontals are wide posteriorly and taper to points anteriorly. Closely applied to each frontal in the region over the orbit is a greatly enlarged scale plate bearing a prominent dorsally oriented thorn-like process (preserved in the holotype and ZPALWr. A/2097) (Figures 3, 4). Because the enlarged supraocular spiny scale is visible in both the largest ( $44.4 \mathrm{~mm} \mathrm{SL})$ and in one of the smaller $(25.0 \mathrm{~mm} \mathrm{SL})$ specimens, we assume that this unique feature among triacanthodids is diagnostic of the new species at all sizes and not just a juvenile character. However, we would not be surprised if the spine on the supraocular scale is relatively smaller in adults larger than our present materials. The prefrontals are well preserved on the holotype and border the anterior wall of the orbit. The indistinct remains of the ethmoid can be seen on the anterior regions of the left frontal (Figures 2, 


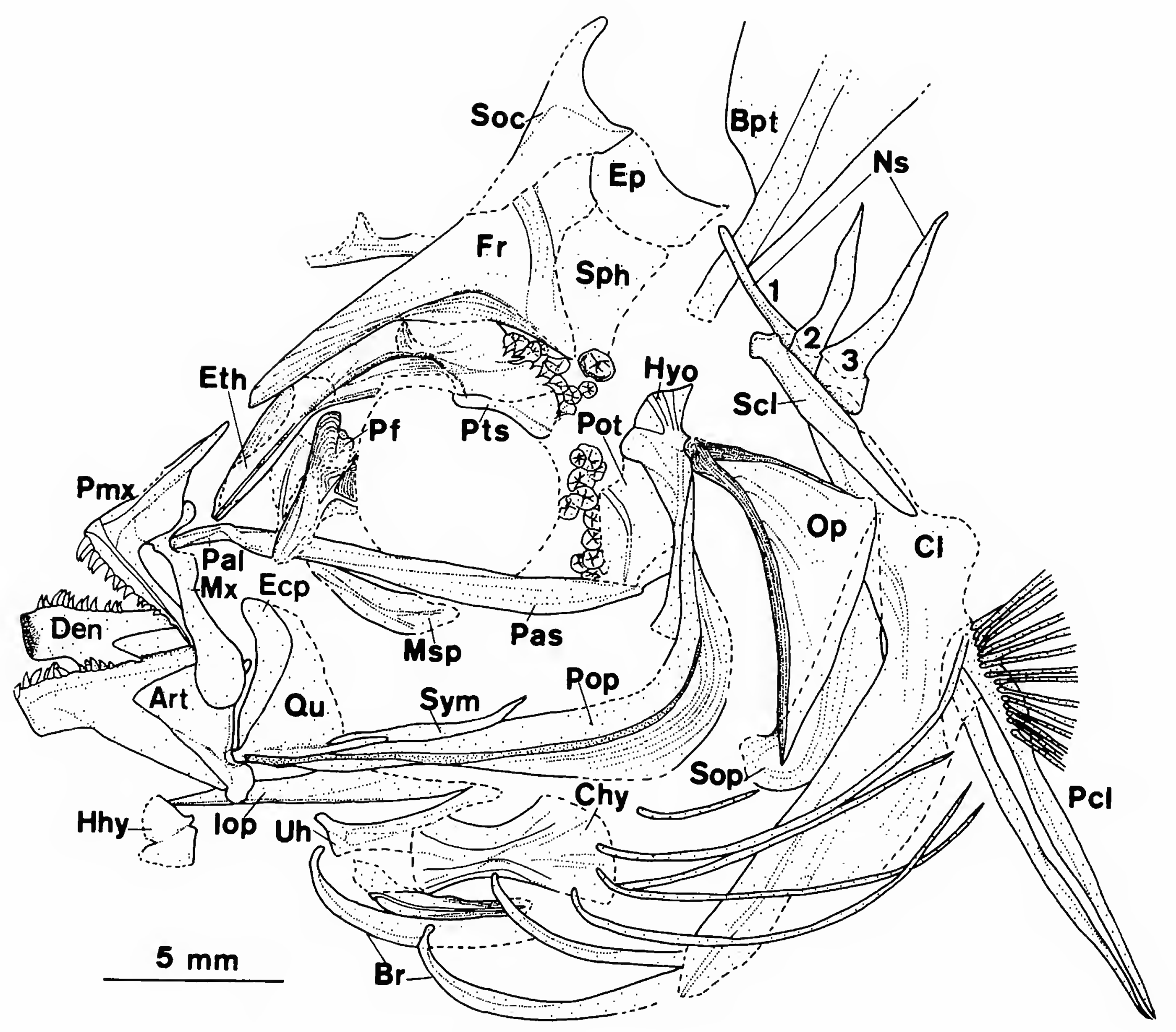

FlGURE 3.-Prohollardia avita, new genus and species, reconstruction of lateral view of skull of holotype.

3). The parasphenoid is relatively straight in the orbital region and has a moderately developed ventral flange (Figure 3 ). Close to the skull of one of the paratypes (ZPALWr. A/2097) are three thin unidentifiable isolated bones that we think are disarticulated pieces of the specimen (Figure $5 \mathrm{~A}-\mathrm{C}$ ).

The jaws are well preserved. The L-shaped premaxilla has a sturdy ascending process and a narrow alveolar process. The maxilla is broadest posteriorly, constricted in the middle, and expanded into an articular facet anteriorly where it meets the palatine and premaxilla in what apparently was a moveable articulation allowing for slight protrusion of the upper jaw. The dentary is broad and concave posteriorly to accommodate its articulation with the articular. The teeth are mostly represented by impressions but were obviously stout, conical, in a single series, and slightly curved posteriorly. There are about 12 to 14 teeth to each side of the upper and lower jaws, based on a combination of the impressions and the space available for missing teeth along the alveolar edge of the bones. We are confident that the teeth are in a single series without additional internal teeth because the left dentary is displaced upward in the holotype and exposed in medial view. The lack of inner series teeth is similar among hollardiins to the condition of Hollardia and in contrast to that of Parahollardia, in which inner series teeth are present.

The hyomandibula is expanded dorsally and tapers to a shaft ventrally. It is oriented almost vertically (Figure 3), unlike the distinctly oblique orientation in all Recent triacanthodids (orientation questionable in the other new Oligocene genus, Carpathospinosus, but probably oblique).

The opercle is a large, thin, almost triangular bone with 


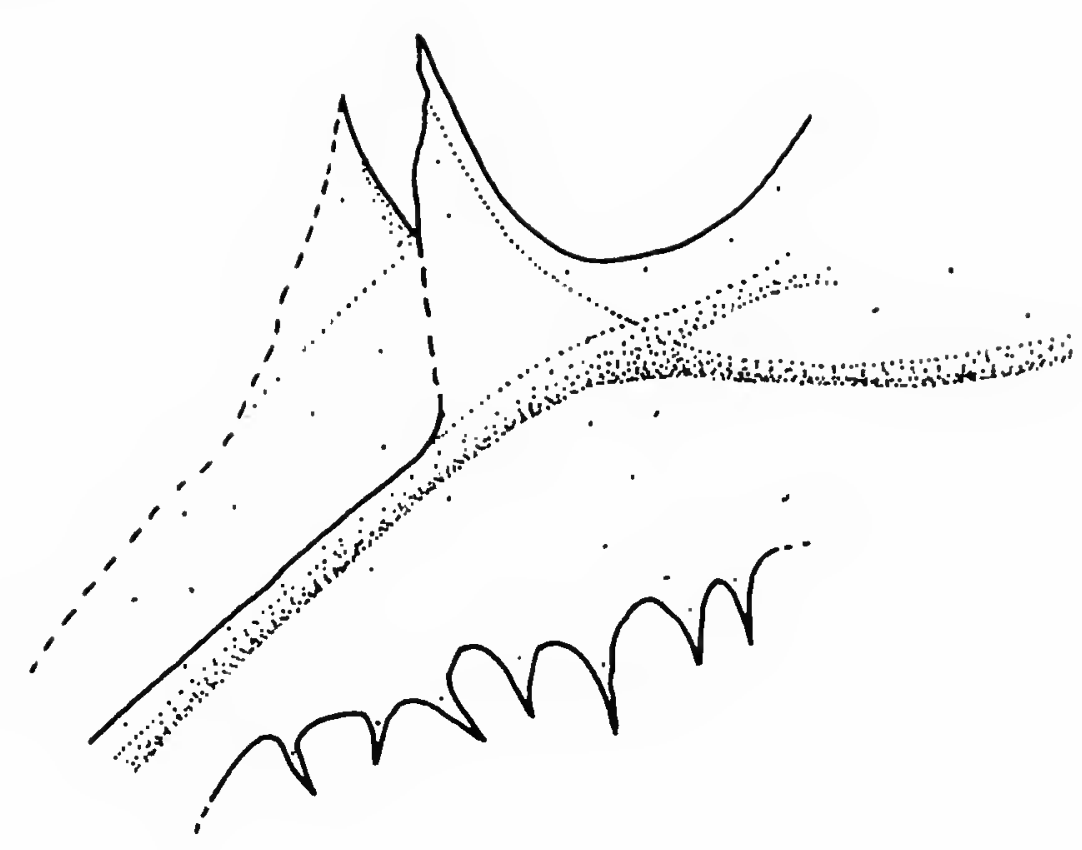

\section{$1 \mathrm{~mm}$}

FIGURE 4.-Prohollardia avita, new genus and species, enlarged right and left supraocular scale plates with thorn-like spines, paratype ZPALWr. A/2097, estimated $25.0 \mathrm{~mm}$ SL (same locality as holotype, see Figure 1).

A
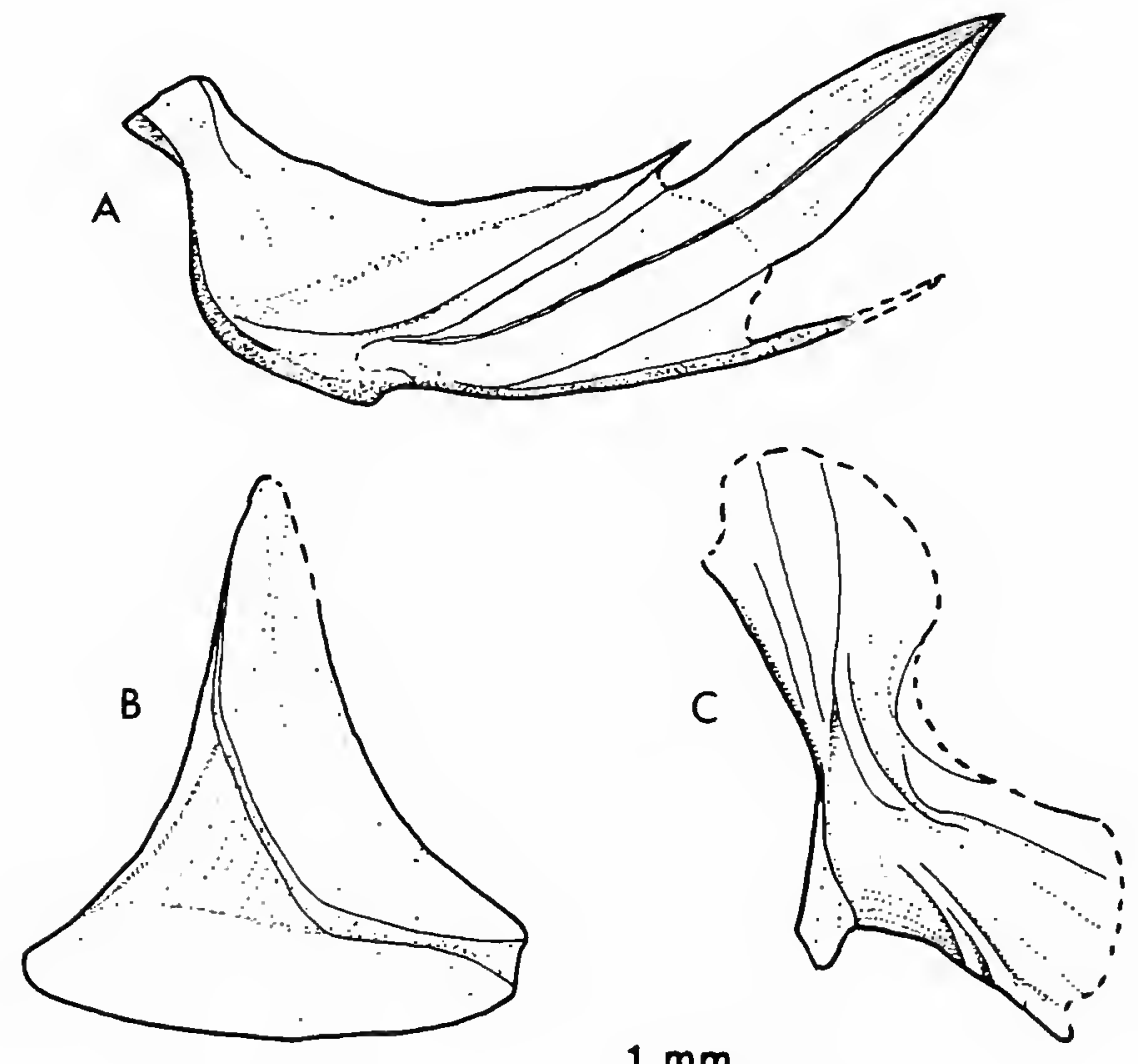

FIGURE 5.-Prohollardia avita, new genus and species, three unidentifiable, isolated bones on plate with paratype ZPALWr. A/2097, all to same scale.

heavy ossification along its anterior and dorsal margins (Figures 3,6). The subopercle is rounded anteroventrally and tapers to a point posterodorsally (Figure 7). The preopercle is strongly curved, with the lower arm about twice as long as the upper and at about a $90^{\circ}$ angle to it. The broad curved regions of the preopercle and subopercle bear fine grooves and ridges

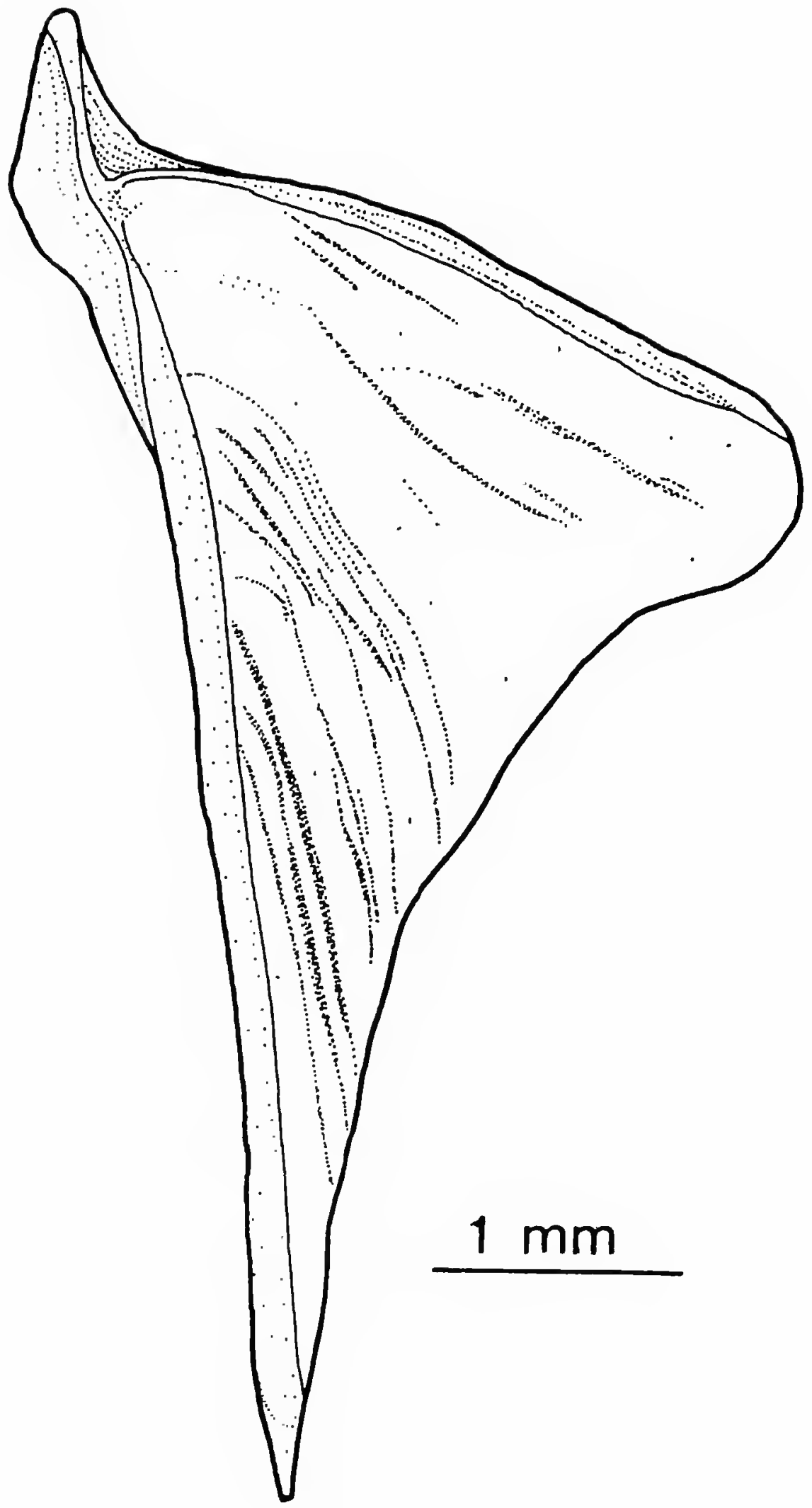

FIGURE 6.-Prohollardia avita, new genus and species, isolated opercle in lateral view, paratype ZPALWr. A/2097.

on their lateral surfaces, approximately parallel to their longest edges (Figures 3,7). The interopercle is visible anteriorly where it is displaced forward beyond the articulation of the lower jaw with the quadrate.

The long ceratohyal is constricted in the middle and broadened posteriorly. The epihyal is not evident. The branchiostegal rays from both sides are somewhat intermixed, but our interpretation of them is that there are six rays of increasing length posteriorly on each side, two in a forward group articulated to the ventral surface of the middle of the ceratohyal and four placed more posteriorly along the side of 


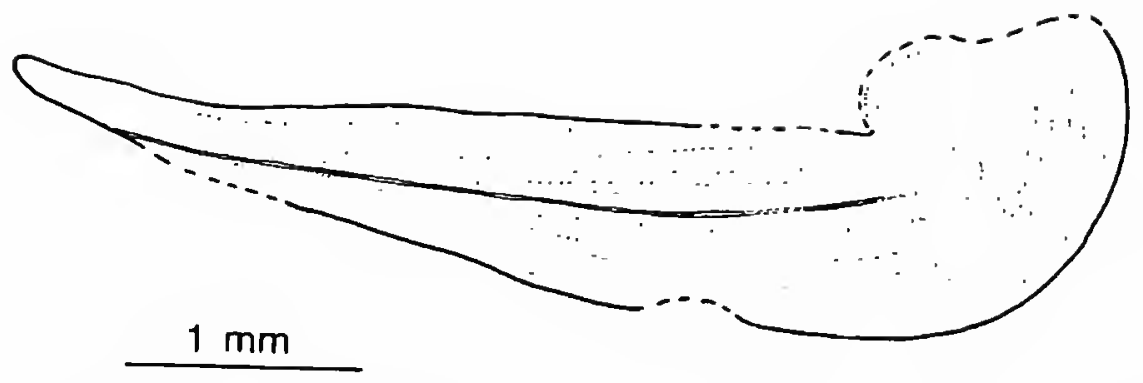

FIGURE 7.-Prohollardia avita, new genus and species, isolated subopercle in lateral view, holotype.

the rear of the ceratohyal and, presumably, the epihyal. The two anterior rays are slightly expanded and flattened while the posterior group are rod-like. In the area below the posterior region of the lower jaw and the anterior end of the interopercle are traces of two bones which we interpret as displaced dorsal and ventral hypohyals (Figure 3).

VERTEBRAL COLUMN.-There are eight abdominal and 12 caudal vertebrae (Figure 2). The neural spine of the first vertebra is directed anteriorly and closely applied to the rear of the neurocranium. This neural spine is presumed to have been bifid (i.e., the two halves not meeting over the neural canal) just as in Recent triacanthodids because the ventral end of the first basal pterygiophore of the spiny dorsal fin passes through it medially to articulate in a cavity in the rear of the skull. All of the other neural spines are non-bifid and posterodorsally oriented. The neural spines of the second and third vertebrae are relatively more vertical than the others, while those of the fourth to seventh vertebrae are more oblique than those that follow. The bases of the neural spines are expanded anteroposteriorly from the second abdominal vertebra to $\mathrm{Pu}_{3}$. Neural foramina are visible on the lateral surfaces of the neural arches on the seventh to ninth caudal vertebrae (Figure 9).

Traces of parapophyses are visible on the last three abdominal vertebrae in the holotype and ZPALWr. A/2097; those on the first two of these vertebrae are shorter and broader than that on the last one (Figure 2). There is no evidence of either pleural or epipleural ribs. Because all Recent triacanthodids and the other new Oligocene genus have epipleurals but lack pleural ribs, we believe that epipleurals were present in Prohollardia but were not preserved. Haemal arches and spines are well developed on the caudal vertebrae. The caudal skeleton is described below.

PECTORAL FIN AND GIRDLE.-Only the elongate supracleithrum and ventral postcleithrum are well preserved. Both are placed obliquely to the axis of the skull, and the latter ends in the region above the posterior half of the pelvis (Figure 2). The cleithrum is only poorly indicated except along its anterior edge.

The pectoral fin has 15 well-preserved intact rays. The short uppermost ray is sturdy, unbranched, and about one-third the length of the second ray, which also appears to be unbranched. The third to 13 th rays are branched.

PeLvic FIn AND GIRDLE.-The pelvis is large, sturdy, and relatively short, with a broad oblique ascending process extending anteriorly from the level of the pelvic spines to what would be the posterior edge of the cleithrum if the pelvis were in its normal position (it is fractured and one part is displaced slightly anteroventrally, Figure 8 ). The pelvis has a stout shaft-like posterior process. The length of the process is $21.4 \%$ SL in the holotype but distinctly shorter, about $14.5 \% \mathrm{SL}$, in the one paratype in which it can be measured (ZPALWr. A/2098). The length of this process in the paratype is much shorter than in other species of triacanthodids, in which the length averages $24 \%-34 \%$ SL (except in the two long-snouted genera, which have a similarly long process relative to the body but lower averages of $19 \%-24 \%$ SL because of the exceptionally long head). The length of the process in the holotype, while relatively short, is, however, comparable to that in some specimens of the hollardiin Hollardia hollardi. In $H$. hollardi the length of the process is more variable than in any other triacanthodid, ranging from $16.3 \%-29.1 \%$ SL (average 24.7), with most specimens having a length of $22 \%$ SL or greater. Specimens of $H$. hollardi in which the process is $16 \%-21 \%$ SL range widely in size, from 53-132 mm SL, with no correlation between the length of the process and standard length (see fig. 145 in Tyler, 1968:335). The relative shortness (20\% SL or less) in the length of the

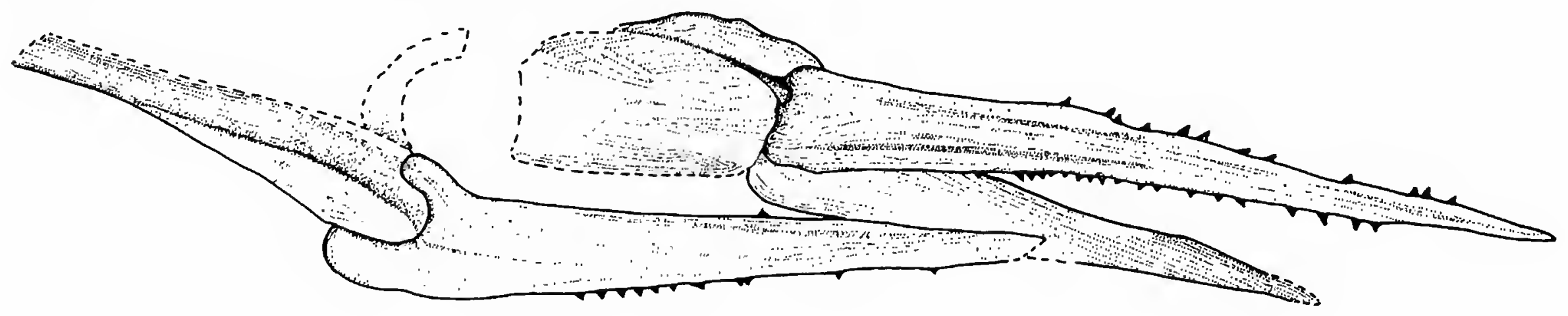

$5 \mathrm{~mm}$

FIGURE 8.-Prohollardia avita, new genus and species, pelvis and pelvic fin in approximately ventral view to right of fracturing indicated by dashed lines and in approximately lateral view to left of fracturing, holotype. 
process is peculiar to Prohollardia avita and to some specimens of $H$. hollardi, and the great variability in its length also is found only in those two species. While longer than in $P$. avita and some specimens of $H$. hollardi, the process in the other new Oligocene genus, Carpathospinosus, is relative shorter $(25.4 \% \mathrm{SL})$ than in most specimens of other species of triacanthodids.

The width of the pelvis between the spines in Prohollardia is $6.7 \% \mathrm{SL}$ in the holotype, the only specimen in which it can be measured. This is relatively broad in comparison to other hollardiins, in which the averages for the five Recent species are $3.6 \%-6.2 \%$ SL. However, the pelvic width, like its length, is highly variable in the Recent hollardiin with the widest pelvis, $H$. hollardi, in which the width ranges from $4.5 \%-8.4 \%$ SL (average 6.2), encompassing the width measurement in Prohollardia. In Prohollardia the pelvic width is contained 3.2 times in the length of the process, while in Recent hollardiins the average values are 4.0-6.7 (with only $H$. hollardi among hollardiins having some specimens with a value as low as 3.2 like that of the single specimen of Prohollardia in which this can be measured).

The two halves of the pelvis apparently are medially fused or consolidated with one another in the largest specimen (the 44.4 $\mathrm{mm}$ SL holotype) but clearly are separate in one of the three smaller specimens (ZPALWr. A/2098, $29.0 \mathrm{~mm} \mathrm{SL}$ ). Fusion of the halves of the pelvis with increasing specimen size also occurs in Recent triacanthodids. In the holotype the pelvic spines and the posterior process are exposed mostly in dorsoventral view, but the ascending process is seen in lateral view.

The length of the strong pelvic-fin spine $(30.1 \%$ SL in the holotype and $19.0 \% \mathrm{SL}$ in the only paratype in which it can be measured, ZPALWr. A/2098) is 1.3-1.4 times (average 1.4) longer than the length of the relatively short posterior process (see measurements above). In Recent triacanthodids the pelvic spines are usually about the same length as the process but sometimes slightly longer (1.1 times) or shorter (0.8-0.9 times). In the other new Oligocene genus, Carpathospinosus, the pelvic spines are exceptionally long and the process exceptionally short, the spine 1.5 times longer than the process.

The pelvic spines bear deep longitudinal grooves and are covered with spinulose scales except at the naked extreme distal tips. There is no evidence of fin rays, but fossil material in this type of shale matrix is unlikely to reveal one or two short or rudimentary rays just behind the base of the pelvic spine such as are found in all Recent triacanthodids.

SPINY DORSAL FIN.-The origin of the spiny dorsal fin (Figure 2) is distinctly anterior to the vertical line through the level of the gill opening, as determined by the well-preserved posterior edge of the opercle and the anterior edge of the cleithrum. In most other triacanthodids the spiny dorsal-fin origin is over or slightly behind the vertical through the level of the gill opening, but it is distinctly posterior to it in the hollardiin Hollardia, over or slightly in front of it in the hollardiin Parahollardia, and distinctly in front of it in the triacanthodin Mephisto (as much so as in Prohollardia). The relative position of the spiny dorsal-fin origin relative to the gill opening in Prohollardia is mostly a function of the longer head and associated more posteriorly located gill opening rather than reflective of a forward migration of the spiny dorsal fin. For example, the predorsal distance (snout to base of first dorsal-fin spine) in Prohollardia averages $57.5 \%$ SL, which is relatively great in comparison to most other triacanthodids (averages $40 \%-50 \%$ SL). However, it is similar to that in two of the three species of Hollardia (averages $55.8 \%$ SL in meadi and $58.8 \%$ SL in hollardi), in which the spiny dorsal-fin origin is slightly to distinctly behind the gill opening. The relatively great predorsal length in these species of Hollardia and in Prohollardia is also partially a function of their greater body depth relative to most other triacanthodids. The spiny dorsal-fin origin is placed over the second centrum in Prohollardia but over the posterior end of the basioccipital or the anterior end of the first vertebra in all other triacanthodids with moderate to great body depths (i.e., exclusive of the somewhat elongate Atrophacanthus and Tydemania, and the much elongate, long-snouted Halimochirurgus and Macrorhamphosodes).

The base of the spiny dorsal fin in Prohollardia (Table 1) is slightly shorter than the base of the soft dorsal fin, whereas in all of the Recent triacanthodids and the Oligocene Carpathospinosus (Table 2) the spiny dorsal-fin base is distinctly longer than the soft dorsal-fin base. The spiny dorsal-fin base is $23.6 \%$ and $19.2 \% \mathrm{SL}$ in the holotype and ZPALWr. A/2099 respectively, versus $26.1 \%$ and $23.0 \%$ SL for the soft dorsal-fin base (Table 1). Comparable measurements for the soft dorsal-fin base (but not the spiny dorsal-fin base) in all Recent triacanthodids are given in Tyler (1968). The lengths of the spiny dorsal-fin base of representative species of most of the Recent genera can be determined from the illustrations of the skeletons in that work. The spiny dorsal-fin base ranges from $26 \%-32 \%$ SL and the soft dorsal-fin base from 16\%-22\% SL in triacanthodids with typical snouts (Table $3 ; 20 \%-21 \% \mathrm{SL}$ and $10 \%-12 \% \mathrm{SL}$ respectively in the two long-snouted genera), with the spiny dorsal-fin base longer.

Prohollardia has six dorsal-fin spines, with all but the short last element bearing deep longitudinal grooves along their lengths. The first spine is strongest, longest, curved posteriorly, and covered with spinulose scales except at the extreme distal tip. The first spine in the holotype is somewhat longer $(28.1 \%$ $\mathrm{SL})$ than the spiny dorsal-fin base $(23.6 \% \mathrm{SL})$, but in the one paratype (ZPALWr. A/2099) in which both measurements can be made the first spine is only marginally longer $(20.7 \% \mathrm{SL})$ than the base (19.2\% SL). If depressed the first dorsal spine in Prohollardia would reach only slightly beyond the origin of the soft dorsal fin. In Recent triacanthodids the first dorsal spine is either shorter or only slightly longer than the spiny dorsal-fin base, reaching posteriorly no more than to the level of the base of about the third to fourth soft dorsal-fin ray. In the other new Oligocene genus, Carpathospinosus, the first dorsal spine is 
especially long (Table 2), of much greater length than the spiny dorsal-fin base.

The length of the second spine is contained 1.6-2.0 times (average 1.8) in that of the first spine (see description of spiny dorsal fin in Carpathospinosus for comparisons with other triacanthodids). The remaining spines decrease gradually in length posteriorly.

The interspinous membranes of Prohollardia are extensively covered with spinulose scales, contrary to conditions in the Oligocene Carpathospinosus and Recent triacanthodids, most of which have no scales on the interspinous membranes. Only the three species of Hollardia among the hollardiins and Johnsonina among the triacanthodins have some scales along the basal part of the interspinous membranes. Even when best developed, as found in $H$. hollardi, the scaly sheath is confined to the basal portions of the fin.

There are five basal pterygiophores, of which the first is the largest and bears the first two spines. The first pterygiophore has well-developed anterior and posterior flanges and a strong columnar central shaft that reaches to what is apparently a concavity on the lower posterior surface of the skull between the exoccipitals and the bifid neural spine of the first vertebra. The second pterygiophore is similar to the first except shorter, narrower, and with a posteroventrally directed shaft reaching to between the neural spines of the third and fourth abdominal vertebrae. The three remaining pterygiophores are progressively smaller and articulate in the interneural spaces of the fifth and sixth to the seventh and eighth vertebrae. No pterygiophore articulates between the neural spines of the fourth and fifth vertebrae. The last pterygiophore is oriented approximately vertically, while in all other triacanthodids the inclination of this pterygiophore is anteroventral.

SOFT DORSAL FIN.-The soft dorsal-fin base is the longest among triacanthodids (Table 3). There are 19 dorsal-fin rays (visible only in holotype), most of which are well preserved only basally. The rays bear spinules laterally, as do those of Recent triacanthodids. Two of the rays in the holotype are complete enough to measure: the fourth is $23 \% \mathrm{SL}$, higher than in any Recent triacanthodid (range $11.4 \%-20.4 \%$ SL, averages 13-19, excluding the long-snouted genera which have lesser values) or the Oligocene Carpathospinosus (about 16\% SL), while the seventh ray is slightly shorter.

There are 13 soft dorsal-fin basal pterygiophores visible (best preserved in the holotype, especially anteriorly). The first and second are oriented approximately vertically and reach ventrally to between the neural spines of the eighth abdominal and first caudal vertebrae. The next 10 basal pterygiophores are variously displaced but overall are relatively less vertical than the first two, while the last is displaced horizontally over the neural spine of the sixth caudal vertebra in the holotype (Figure

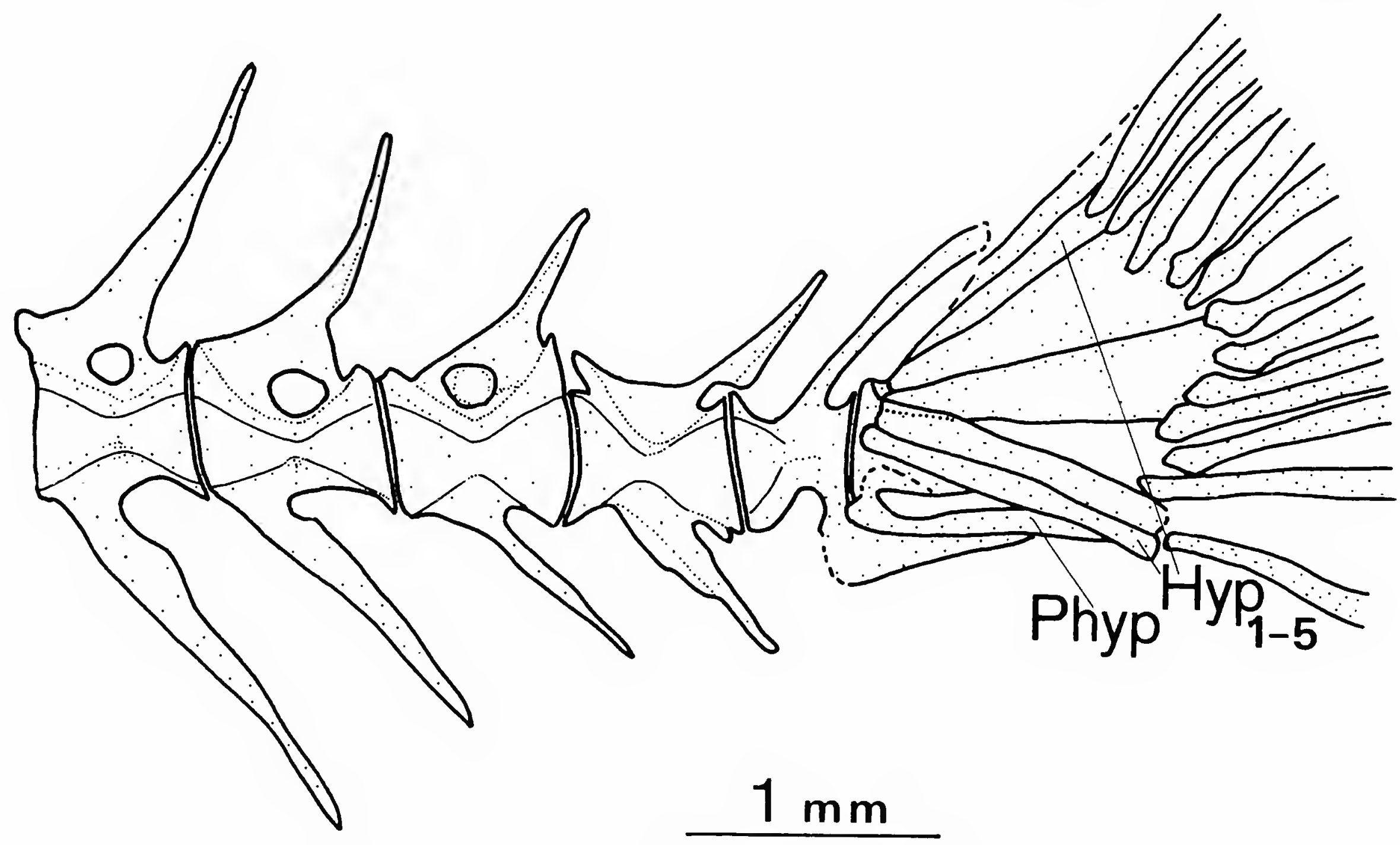

FIGURE 9.-Prohollardia avita, new genus and species, caudal fin and skeleton, holotype. 
2). The vertical orientation of the first two pterygiophores in Prohollardia is unique among triacanthodids, which otherwise have all of the pterygiophores inclined anteroventrally.

ANAL FIN.-There are 15 anal-fin rays (holotype and ZPALWr. A/2098), incomplete distally (it remains to be seen whether the anal fin in Prohollardia is as uniquely high as the soft dorsal fin). The bases of the rays are spinulose. The first basal pterygiophore is the largest in the series. None of the basal pterygiophores has the distal region preserved and it therefore is impossible to determine whether an anteromedial flange was present, as in Recent hollardiins and in Carpathospinosus alone among the triacanthodins.

CAUDAL FIN AND SKELETON.-There are 12 caudal-fin rays, with only the basal parts preserved. The details of the caudal skeleton are poorly preserved but a parhypural and at least five separate hypurals are evident in the holotype (Figure 9). The element above the fifth hypural may be either a sixth hypural, an epural, or a uroneural. The third and fourth hypurals are the largest, and the first and second are displaced and partially cover the distal end of the parhypural. In the holotype the neural spine on $\mathrm{Pu}_{2}$ is longer than that on $\mathrm{Pu}_{3}$.

SCALES.-Spinulose scales completely cover the head, body, spiny dorsal-fin membranes, and all but the extreme distal tips of the dorsal and pelvic spines (Figure 2).

The rounded basal plates of most of the scales in the holotype (Figure 10A-C) bear a single upright spinule, but a few have three spinules, with the central one the largest. A single spinule is present on the scale plates in the smaller specimens. There are star-like radiations around the bases of the spinules. These are typical numbers and shapes of the spinules for small specimens of triacanthodids.

\section{Subfamily TriacanthodinaE Tyler (1968)}

This subfamily includes 15 species in nine Recent genera from the Indo-western Pacific (8 of the 9) and western Atlantic oceans and the new Oligocene genus Carpathospinosus from the Polish Carpathian Mountains.

Carpathospinosus has a flat supraoccipital bearing a small crest anteromedially, the epiotics meeting medially on the dorsal surface of the skull, the epiotics separated from the frontals by the sphenotics, and a broad basin-like posterior process of the pelvis. These are diagnostic characteristics of the subfamily Triacanthodinae. Three of the defining characteristics of the triacanthodins are here hypothesized to be derived and establish the monophyly of the subfamily (see "Discussion of Subfamilial Defining Characters").

\section{Carpathospinosus, new genus}

TYPE SPECIES.-Carpathospinosus propheticus, new species, by monotypy and present designation.
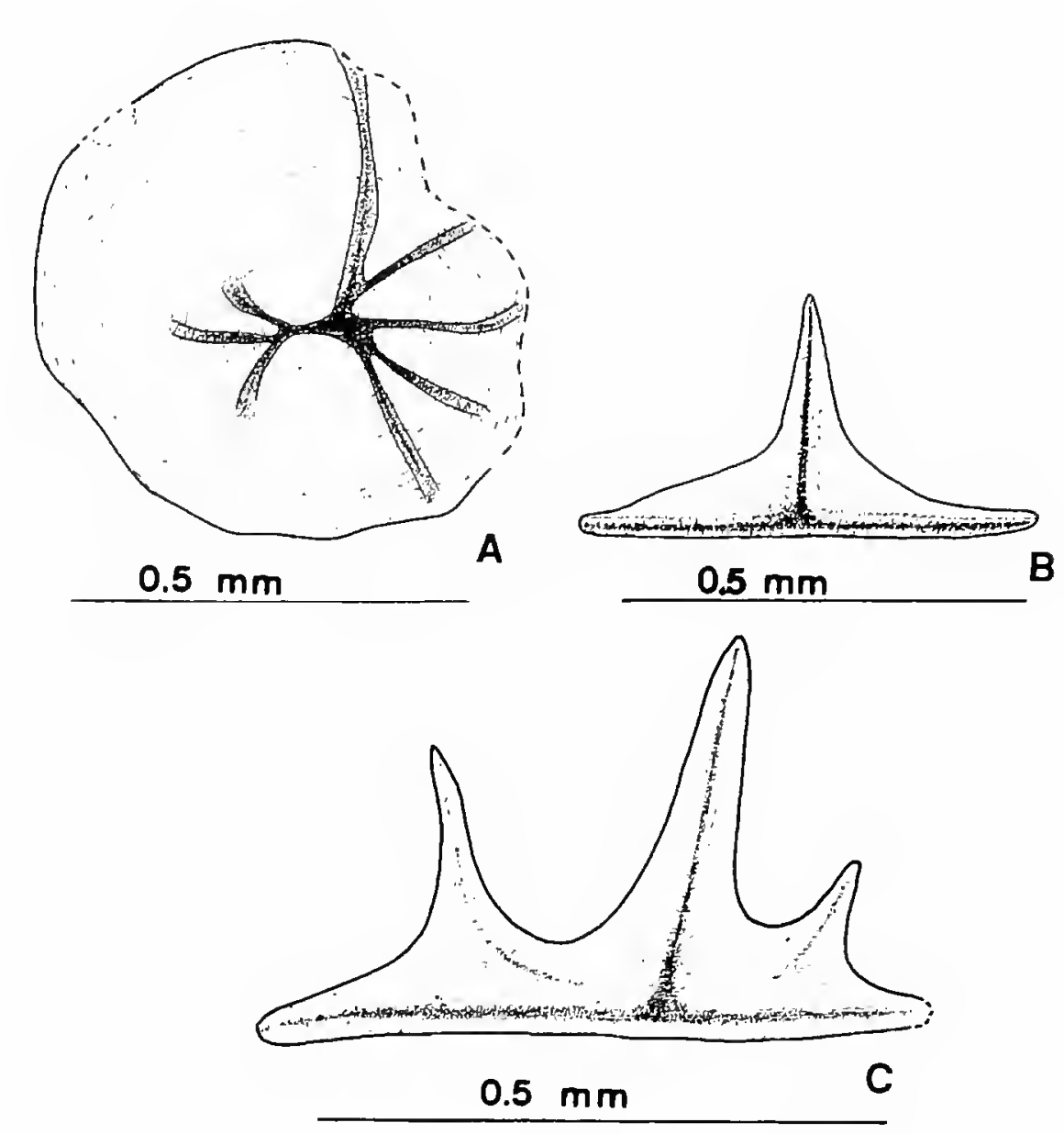

FIGURE 10.-Prohollardia avita, new genus and species, scales, holotype: A, basal plate in dorsoventral view; B, C, scales with one and three upright spinules in lateral view.

ETYMOLOGY.-Carpatho, found in the Carpathian Mountains; and the Latin spinosus for the large size of the first dorsal spine and for the pelvic spine; masculine.

\section{DIAGNOSIS}

Carpathospinosus differs from all other Triacanthodidae by the first dorsal spine with a longer average relative length (37\% SL versus $24 \%-34 \%$ ) and the second dorsal spine considerably shorter, with an average relative length at the low end of the range of length in other triacanthodids (15\% SL versus $13 \%-29 \% \mathrm{SL}$ ), its length contained an average of 2.4 times in the length of the first spine (versus length of second spine contained an average of 1.1-1.4 times in length of first spine in Recent triacanthodids and 1.8 times in the Oligocene Prohollardia).

Carpathospinosus differs from all other Triacanthodinae by the presence of an anteromedial flange on the first basal pterygiophore of the anal fin (versus flange absent); the pelvic spine much longer than the length of the posterior process of the pelvis, the process contained about 1.5 times in the length of the spine (versus pelvic spine usually shorter but sometimes as long as or very slightly longer than the process, the process contained about 0.8 to 1.1 , usually 1.0 , times in the length of the spine); the head especially long, about $45 \%$ SL (versus averages of $35 \%-41 \%$ SL except in the two long-snouted genera). The relative width of the pelvis in Carpathospinosus is 
greater than in any other triacanthodin except the Recent Bathyphylax.

\section{Carpathospinosus propheticus, new species}

FIGURES 11-19; TABLE 2

MATERIAL.-Holotype, ZPALWr.A/3000, an almost complete specimen in part and counterpart, with only the anterior part of the lower jaw missing, $33.4 \mathrm{~mm}$ SL. Nine paratypes, ZPALWr.A/3001-A/3009, about 12.0-33.0 mm SL, less complete and less well preserved than the holotype, all in part and counterpart (some fragmentary): ZPALWr. A/3001, about $25.0 \mathrm{~mm}$ SL, incomplete; ZPALWr. A/3002, about 29.0 $\mathrm{mm}$ SL, without anterior part of spiny dorsal fin; ZPALWr. A/3003, about $16.0 \mathrm{~mm} \mathrm{SL}$, without caudal fin; ZPALWr. A/3004, about $25.0 \mathrm{~mm} \mathrm{SL}$, without anterior part of head and first dorsal spine; ZPALWr. A/3005, about $30.0 \mathrm{~mm}$ SL, part of postcranial skeleton without dorsal and caudal fins; ZPALWr. A/3006, about $25.0 \mathrm{~mm} \mathrm{SL}$, without anterior part of head and posterior end of body; ZPALWr. A/3007, about 12.0 $\mathrm{mm}$ SL, parts of head, vertebral column, and spiny dorsal fin; ZPALWr. A/3008, $33.0 \mathrm{~mm}$ SL, mostly isolated bones; ZPALWr. A/3009, about $18.0 \mathrm{~mm}$ SL, nearly complete.
There are 10 other highly fragmentary or poorly preserved specimens from the same formation of what are probably Carpathospinosus but since we cannot be absolutely certain of their specific identity we do not designate them as paratypes.

All but one of the specimens are impressions in siliceousargillaceous shales; the exception is ZPALWr. A/3002, which is in laminated limestones as partially preserved bones, spines, and fin rays in both plates.

TYPE HORIZON.-Upper Oligocene, zone IPM 4 of the Menilite Beds.

TYPE LOCALITY.-Przysietnica, northwest of Sanok, Krosno Province, the Carpathians, southeast Poland $\left(49^{\circ} 44^{\prime} \mathrm{N}\right.$, $22^{\circ} 03^{\prime} \mathrm{E}$ ).

DIAGNOSIS.-As for the genus.

ETYMOLOGY.-From the Greek prophetes, in allusion to the first known occurrence of the wide basin-like posterior process of the pelvis that is characteristic of the triacanthodin lineage of triacanthodid evolution; masculine.

\section{DESCRIPTION}

Judging from the sizes of the various life history stages of the Recent species of the family, the holotype (Figures 11,12) is

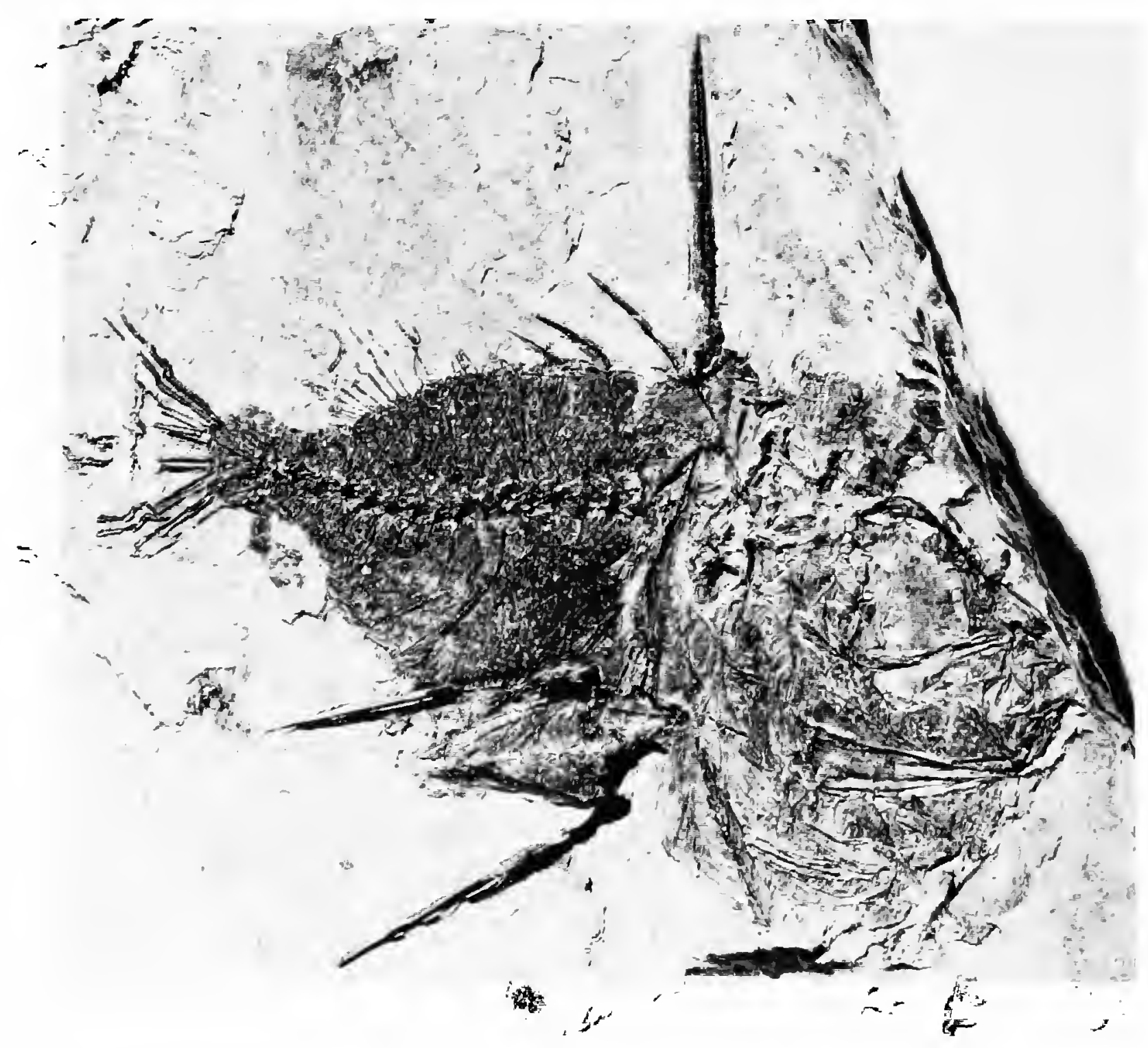

FIGURE 11.-Carpathospinosus propheticus, new genus and species, photograph of holotype, ZPALWr. A/3000, $33.4 \mathrm{~mm}$ SL, Menilite Beds, IPM 4, Przysietnica, southern Poland, Carpathian Mountains, Upper Oligocene. 


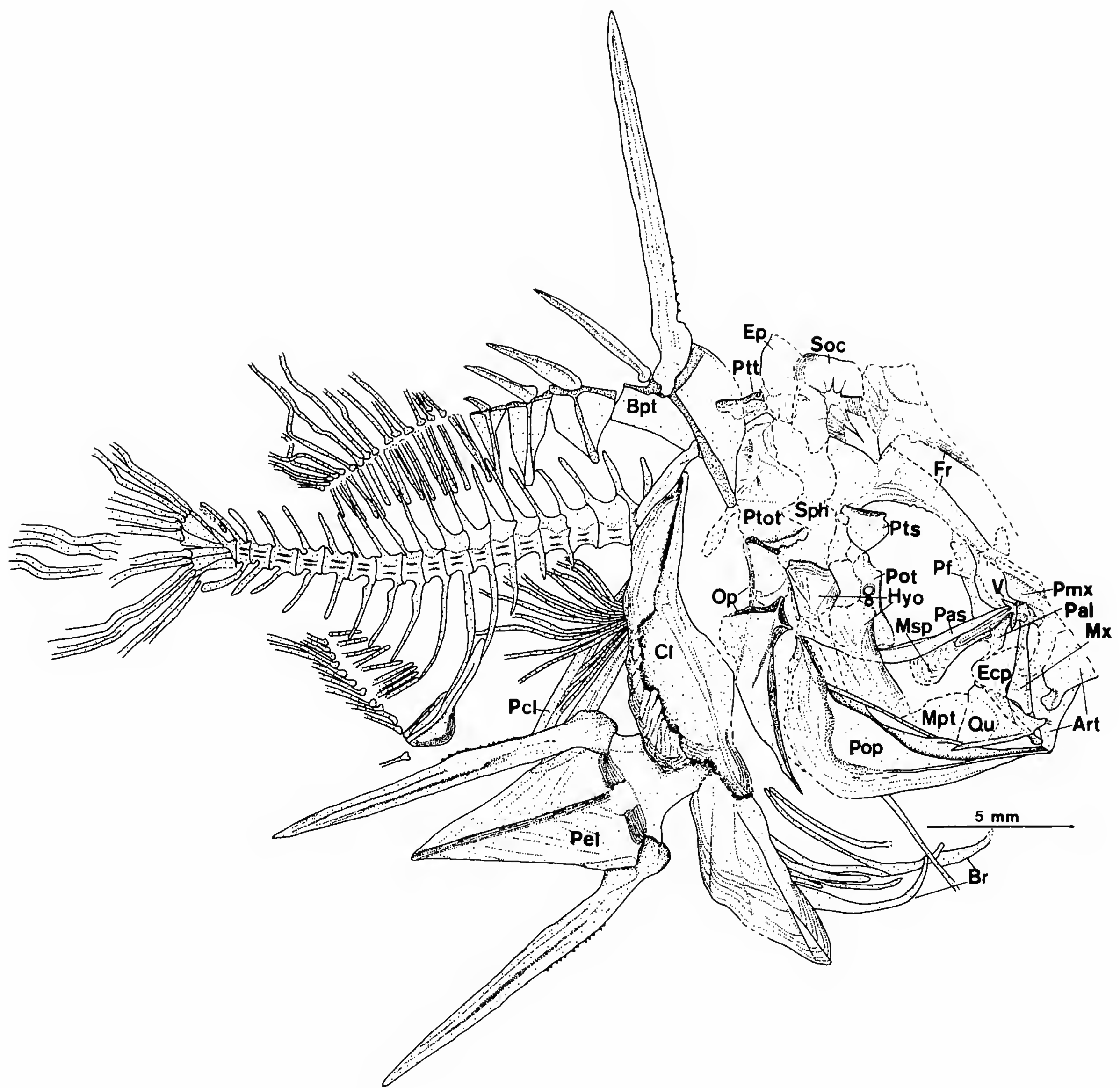

FIGURE 12.-Carpathospinosus propheticus, new genus and species, reconstruction based on holotype.

probably a young adult and the seven larger paratypes are probably juveniles. The three smallest paratypes, ZPALWr. A/3007, ZPALWr. A/3003, and ZPALWr. A/3009, respectively about 12,16 , and $18 \mathrm{~mm} \mathrm{SL}$, could be postlarvae or recently settled juveniles. Measurements for two of the specimens are given in Table 2.

The maximum depth of the body is $50.0 \%$ SL in the holotype, the only specimen in which it can be accurately measured, comparable to that in small specimens of several other triacanthodins (e.g., Triacanthodes and Johnsonina, see Tyler, 1968:126, figs. 152, 166).

HEAD.-The head (Figure 13) is relatively long, $45.5 \%$ SL in the holotype, the only specimen in which it can be accurately measured. The Oligocene hollardiin Prohollardia has a longer head (average $49.5 \%$ SL) than Carpathospinosus but among Recent triacanthodins with typical heads (i.e., excluding the two genera with elongate snouts) the head length averages $35 \%-41 \%$ SL. In triacanthodids the head is proportionally 
TABLE 2.-Measurements of Carpathospinosus propheticus, new genus and species.

\begin{tabular}{|c|c|c|c|c|}
\hline \multirow{3}{*}{ Character } & \multicolumn{2}{|c|}{ Holotype } & \multicolumn{2}{|c|}{ Paratype } \\
\hline & \multicolumn{2}{|c|}{ ZPALWr.A/3000 } & \multicolumn{2}{|c|}{ ZPALWr.A/3001 } \\
\hline & $\mathrm{mm}$ & $\%$ SL & $\mathrm{mm}$ & $\%$ SL \\
\hline Standard length & 33.4 & & $25.0^{*}$ & \\
\hline Head length & 15.2 & 45.5 & - & \\
\hline Body depth & 16.7 & 50.0 & - & \\
\hline Predorsal length & 17.5 & 52.3 & 12.5 & $50.0^{*}$ \\
\hline First dorsal spine & 13.0 & 38.9 & 8.7 & $34.8^{*}$ \\
\hline Second dorsal spine & 5.3 & 15.8 & 3.7 & $14.8^{*}$ \\
\hline Third dorsal spine & 3.6 & 10.7 & - & - \\
\hline Pelvic spine & 13.0 & 38.9 & - & - \\
\hline Pelvis width & 4.4 & 13.1 & - & - \\
\hline Pelvis length & 8.5 & 25.4 & & - \\
\hline Spiny-dorsal base & 9.0 & 26.9 & - & - \\
\hline Soft-dorsal base & 5.1 & 15.2 & & - \\
\hline Anal base & 5.0 & 14.9 & & - \\
\hline
\end{tabular}

*Value is approximate.

longest in juveniles and the greatest lengths recorded for those with typical snouts are $44.7 \%$ SL in both a $23.7 \mathrm{~mm} \mathrm{SL}$ specimen of the hollardiin Hollardia hollardi and a $18.1 \mathrm{~mm}$ SL specimen of the triacanthodin Johnsonina eriomma. Because the holotype of Carpathospinosus is relatively small and has an only marginally longer head than in these two small specimens of other triacanthodids, we do not consider this difference significant.

The supraoccipital is flat and bears a small crest anteromedially, as seen in dorsal view on the holotype (Figure 13) and ZPALWr. A/3001. The epiotics meet medially on the dorsal surface of the skull and are separated anteriorly from the frontals by the sphenotics. The well-preserved prootic in the holotype is displaced slightly into the orbit, and bears two neural foramina of the trigemino-facialis chamber. The long frontals are wide posteriorly and taper to points anteriorly. Only the straight middle part of the parasphenoid in the lower region of the orbit is preserved. There is a faint trace of the prefrontal at the front of the orbit.

The jaws are typical for triacanthodids, with the L-shaped premaxilla having a long ascending process (best seen in ZPALWr. A/3009). The lower jaw is much deeper posteriorly than anteriorly and has a slightly concave ventral edge. There are at least 12 and perhaps a few more small conical teeth to each side of the upper and lower jaws (best seen in ZPALWr. $\mathrm{A} / 3009$ ).

None of the specimens have the upper and lower jaws well-enough preserved and appropriately exposed for it to be determined whether inner series teeth were present.

The hyomandibula is only exposed in the holotype, and only as two large fragments, the dorsal head from the left side and the ventral shaft from the right side. The dorsal head may be slightly displaced anteriorly because it appears to articulate mainly with the sphenotic rather than about equally with the pterotic and sphenotic. The piece representing the ventral shaft of the hyomandibula is oriented obliquely but displaced significantly anteriorly. It is impossible to determine whether the hyomandibula in its natural position had an oblique orientation as in all Recent triacanthodids, but we have no reason to believe that it was oriented vertically as in Prohollardia.

The opercle is triangular and it and the anterior part of the subopercle bear a series of ridges and furrows parallel to their margins (best seen in ZPALWr. A/3004). The long preopercle (Figure 14) is bent slightly more than $90^{\circ}$; on the isolated preopercle of ZPALWr. A/3008 a large lamina dorsalis is visible. The ceratohyal and the branchiostegal rays are not well preserved.

VERTEBRAL COLUMN.- There are eight abdominal and 12 caudal vertebrae (Figure 12). In ZPALWr. A/3006 the first abdominal vertebra is displaced and exposed in posterior view (Figure 15). The right and left halves of its neural spine are separate, without a roof over the neural canal. This bifid neural arch and spine presumedly attached to the rear of the skull and enclosed the ventral shaft of the first basal pterygiophore of the spiny dorsal fin, as in all other triacanthodids. The remaining neural spines are fused in the midline and inclined posterodorsally. Wide parapophyses and enlarged bases of the neural spines on the last three abdominal vertebrae are apparent in ZPALWr. A/3007 and, to a lesser extent, ZPALWr. A/3006. Traces of epipleurals are preserved in the latter specimen. Haemal arches and spines are well developed on the caudal vertebrae, with those on $\mathrm{Pu}_{2}$ being longer and stronger than the others in the caudal peduncle. The caudal skeleton is described below.

PECTORAL FIN AND GiRDLE.-The large cleithrum is expanded posteroventrally, bluntly rounded anteriorly, and tapered to a point dorsally (Figure 16). Like the opercular bones, the cleithrum bears a series of fine ridges and furrows parallel to its edges and has an anterior crest along its midportion. The narrow supracleithrum is placed distinctly obliquely to the axis of the skull. The postcleithra are represented by only the poorly preserved right and left halves of the ventral postcleithrum. Traces of 14 pectoral-fin rays and of three actinosts are visible in ZPALWr. A/3002.

PELVIC FIN AND GIRDLE.-The halves of the basin-like posterior process of the pelvis have a flat ventral expanse with upturned lateral edges; their medial edges are in close contact but unfused in the midline (Figure 17). The process can be measured only in the holotype. It is exceptionally wide, its width contained 1.9 times in its length. In all other triacanthodins except the genus Bathyphylax the process is substantially narrower, with width into length averages in the species with typical snouts of 2.8 to 5.2. In the two species of Bathyphylax the process is as wide as in Carpathospinosus, having average width into length ratios of 1.9 and 2.3. In the two long-snouted genera of triacanthodins the process is narrow (average ratios of 4.2 to 6.1$)$. 


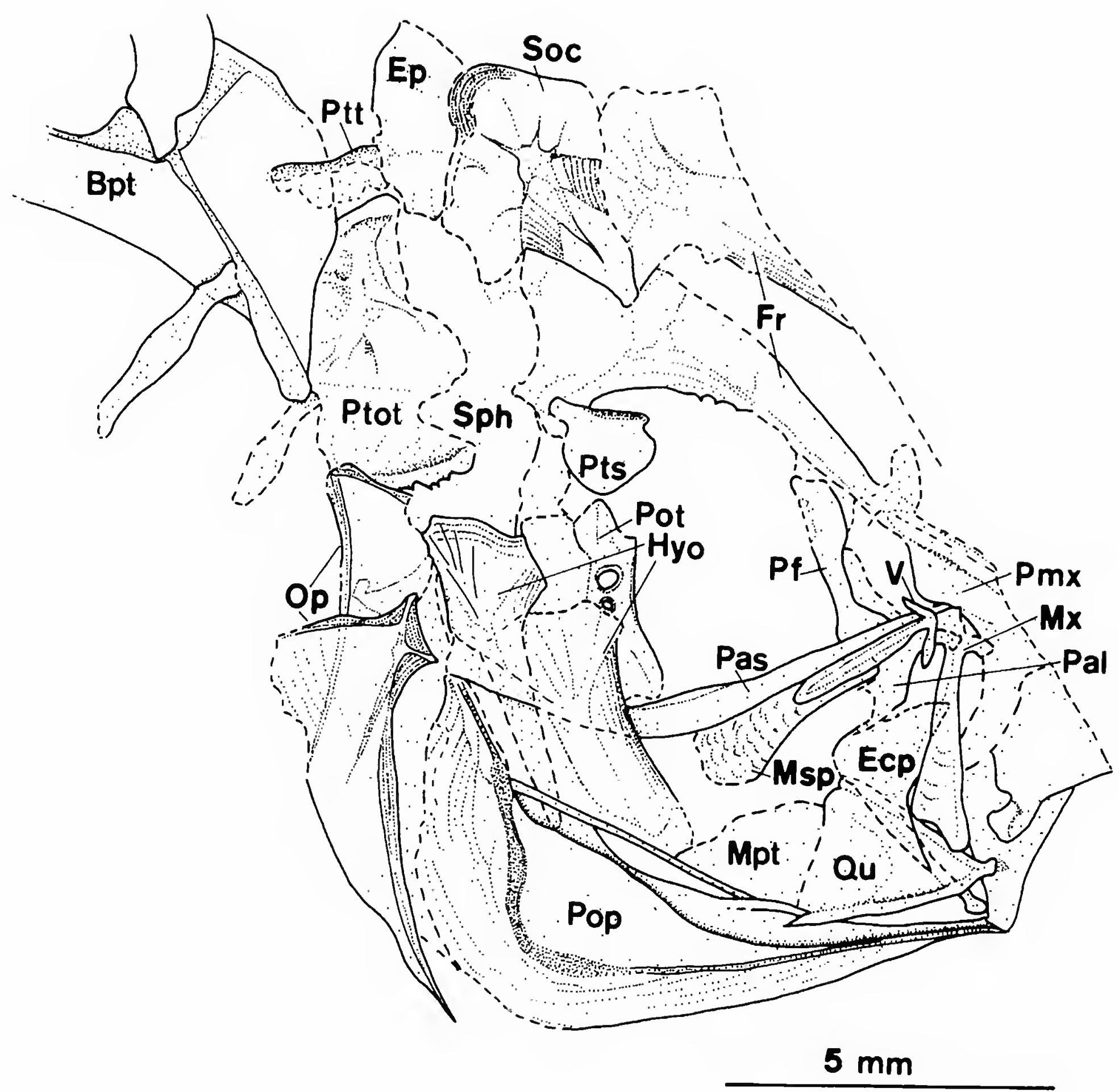

FIGURE 13.-Carpathospinosus propheticus, new genus and species, reconstruction of lateral view of skull of holotype.

The pelvic fin consists of a long strong spine, the basal one-half to two-thirds of which is covered with spinulose scales. There is no evidence of fin rays. The length of the spine (only fully preserved in the holotype) is much greater, about 1.5 times, than that of the relatively short posterior process of the pelvis. In all Recent triacanthodids the pelvic spine is approximately the same length as the process, with average ratios of 0.8 to 1.1 , and usually 1.0 . The Oligocene hollardiin Prohollardia, with a moderate pelvic spine length but a short process, has a process into spine ratio of 1.3-1.4, intermediate between that of Recent triacanthodids and Carpathospinosus. However, we doubt that the situation in Carpathospinosus, with a basin-like process and exceptionally long pelvic spines, is comparable to that in Prohollardia, with a shaft-like process

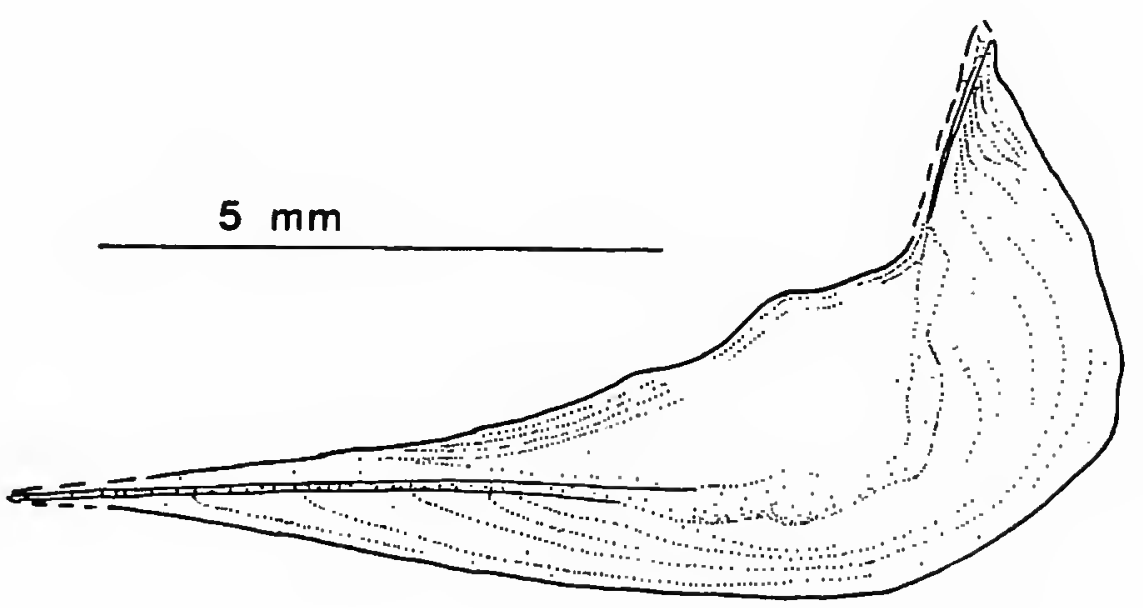

FIGURE 14.-Carpathospinosus propheticus, new genus and species, isolated preopercle in lateral view, paratype ZPALWr. A/3008, $33.0 \mathrm{~mm}$ SL (same locality as holotype, see Figure 11). 


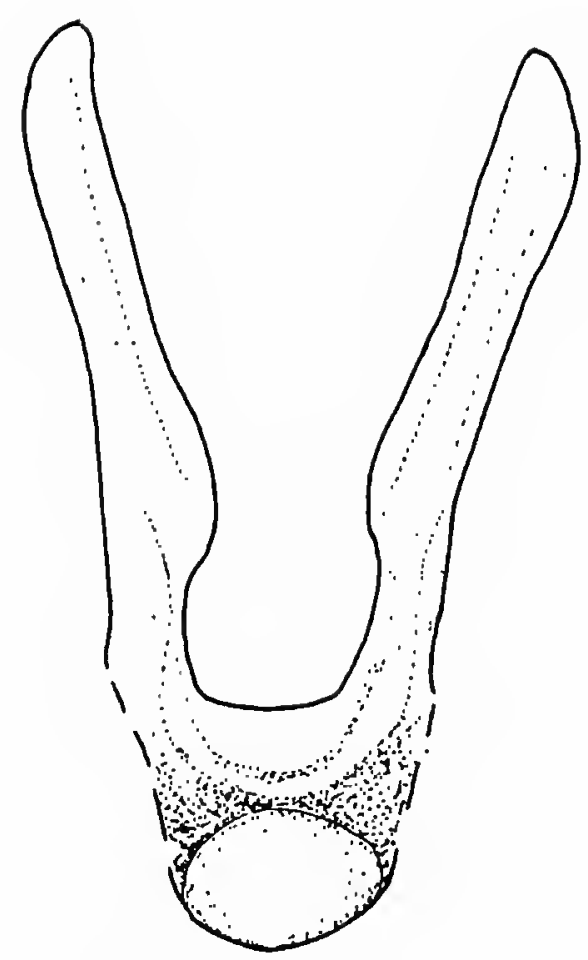

$1 \mathrm{~mm}$

FIGURE 15.-Carpathospinosus propheticus, new genus and species, isolated firsi abdominal vertebra in posterior view, paratype ZPALWr. A/3006, about $25.0 \mathrm{~mm}$ SL (same locality as holotype, see Figure 11).
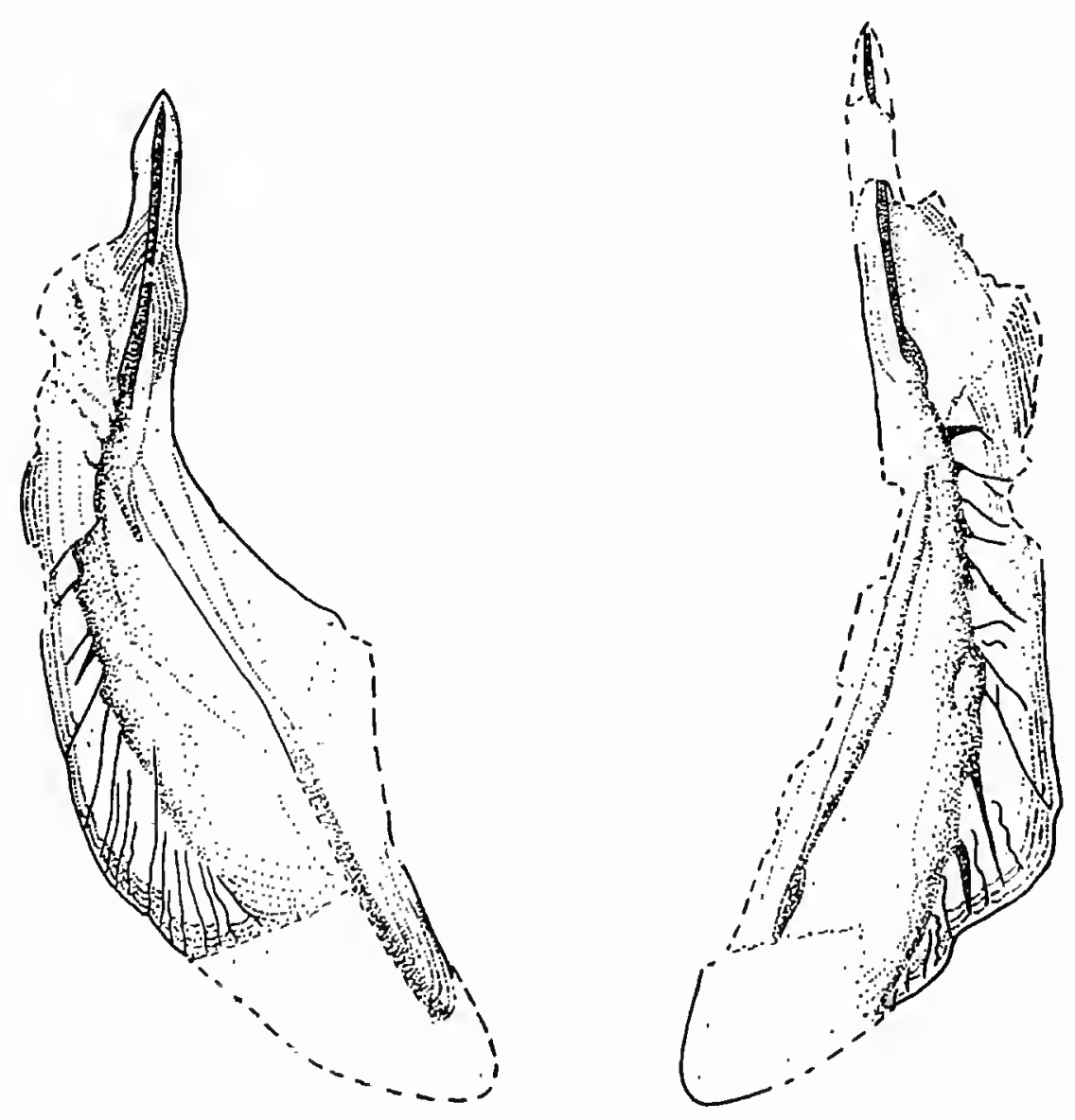

\section{$1 \mathrm{~mm}$}

FIGURE 16.-Carpathospinosus propheticus, new genus and species, left and right cleithra in lateral view, holotype.

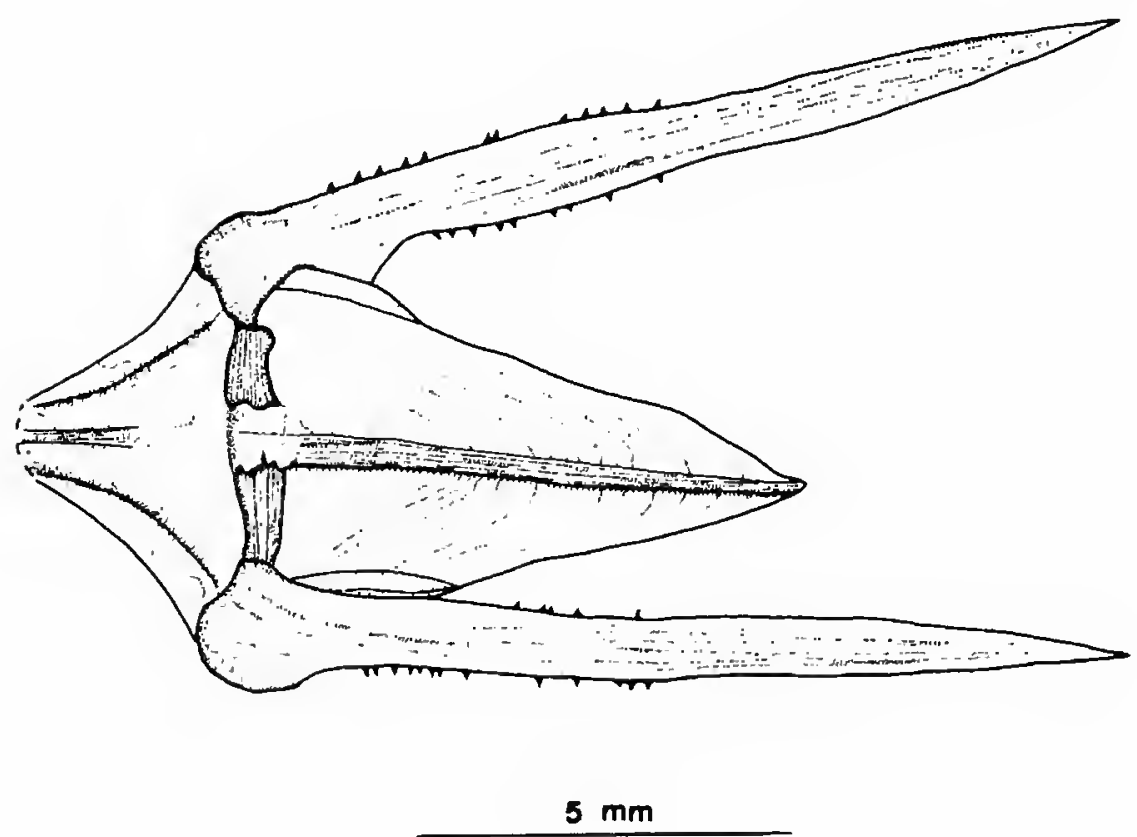

FIGURE 17.-Carpathospinosus propheficus, new genus and species, pelvis and pelvic fin in ventral view, holotype.

of highly variable length and more typical pelvic spine relative length.

SPINY DORSAL FIN.-The spiny dorsal-fin base is much longer than the soft dorsal-fin base, typical of all other triacanthodids except the Oligocene hollardiin Prohollardia, which has a shorter spiny dorsal-fin base. The origin of the spiny dorsal fin is distinctly behind the vertical through the posterior margin of the gill opening. Five dorsal spines are visible on the holotype, with a sixth probably present based on faint traces of a basal pterygiophore (sequentially fifth) that would have supported it (Figure 12). When depressed the long first spine (Table 2) would have reached approximately to the vertical through the base of the eleventh soft dorsal-fin ray, far more posteriorly than in any other triacanthodid. The first spine has longitudinal grooves and spinulose scales (bearing a single upright process) that cover the basal one-third to one-half of its length.

The first spine is much longer $(38.9 \%$ and $34.8 \% \mathrm{SL}$, average 36.9 , holotype and ZPALWr. A/3001, respectively) than the second spine (15.8\% and $14.8 \%$ SL, average 15.3 ), with the length of the second spine contained an average of 2.4 times in the length of the first spine (Table 3). In Recent triacanthodids the second spine is only slightly shorter than the first. Average values for all species with typical heads are $20.9 \%-33.8 \%$ SL for the first spine, $15.4 \%-28.8 \%$ SL for the second spine (the long-snouted genera have lesser values), and 1.1-1.4 for the second spine into the first. In the Oligocene Prohollardia the length of the first spine is at the low end of the range of values in most other triacanthodids of comparable size, while the length of the second spine is slightly less than in other species. The ratio of the length of the second spine into that of the first in Prohollardia is 1.8, intermediate between that of Carpathospinosus and Recent triacanthodids, just as is the case with the pelvic process into pelvic spine ratio. In neither case, 
however, are the intermediacy of these values in Prohollardia achieved in a comparable manner to those in Carpathospinosus.

The second to fifth (and presumedly sixth) dorsal spines in Carpathospinosus decrease gradually in length posteriorly. The spiny dorsal-fin membrane is scaleless, except for a single series of scales along its base that is continuous with those of the body.

The five basal pterygiophores of the spiny dorsal fin decrease gradually in anteroposterior width posteriorly. The first basal pterygiophore bears the first two spines. It is inclined anteroventrally, extends between the bifid neural spine of the first vertebra, and articulates closely with the rear of the skull. The second pterygiophore is oriented slightly anteroventrally in the space between and above the neural spines of the third and fourth vertebrae, while the space between the neural spines of the fourth and fifth vertebrae is vacant. The third and fourth pterygiophores are oriented, respectively, vertically and slightly anteroventrally and insert between the neural spines of the fifth and sixth and sixth and seventh vertebrae. The narrow anteroventrally inclined fifth pterygiophore inserts between the neural spines of the seventh and eighth vertebrae.

SOFT DORSAL FIN.- There are about 15 dorsal-fin rays, which are only well preserved basally. Traces of the distal regions of some of the rays in the holotype indicate that the greatest fin height was about $16 \%$ SL, like other triacanthodids except the Oligocene Prohollardia, in which the fin is much higher. All of the basal pterygiophores of the soft dorsal fin are narrow and inclined anteroventrally.

ANAL. FIN.-The basal regions of 12 fin rays are visible but the distal regions are essentially absent. The first basal pterygiophore is the largest, and bears a prominent anteromedial crest or flange along most of the ventral half of its length. Such a flange is absent in Recent triacanthodins but present in Recent hollardiins (condition unknown in the Oligocene Prohollardia).

CAUDAL FIn AND SKELETON.-There are 12 caudal-fin rays, which are only well preserved basally. The caudal skeleton (Figure 18) is poorly preserved, especially dorsally where only one, incomplete, epural is visible. In the holotype the neural spine of $\mathrm{Pu}_{2}$ is longer than that of $\mathrm{Pu}_{3}$ (Figure 12). Five separate hypurals are evident, with the uppermost rod-like and the fourth the deepest. The parhypural is autogenous.

SCALES.-Spinulous scales completely cover the head, body, and distal one-half to two-thirds of the first dorsal and pelvic spines. Each of the rounded basal plates has a single upright spinule from whose base there are star-like radiations (Figure 19).

\section{Other Relevant Fossil Taxa}

The status of fossils previously referred to the triacanthodids and triacanthids needs to be clarified to assist the discussion of the placement of the two new Oligocene genera. In his phenetic

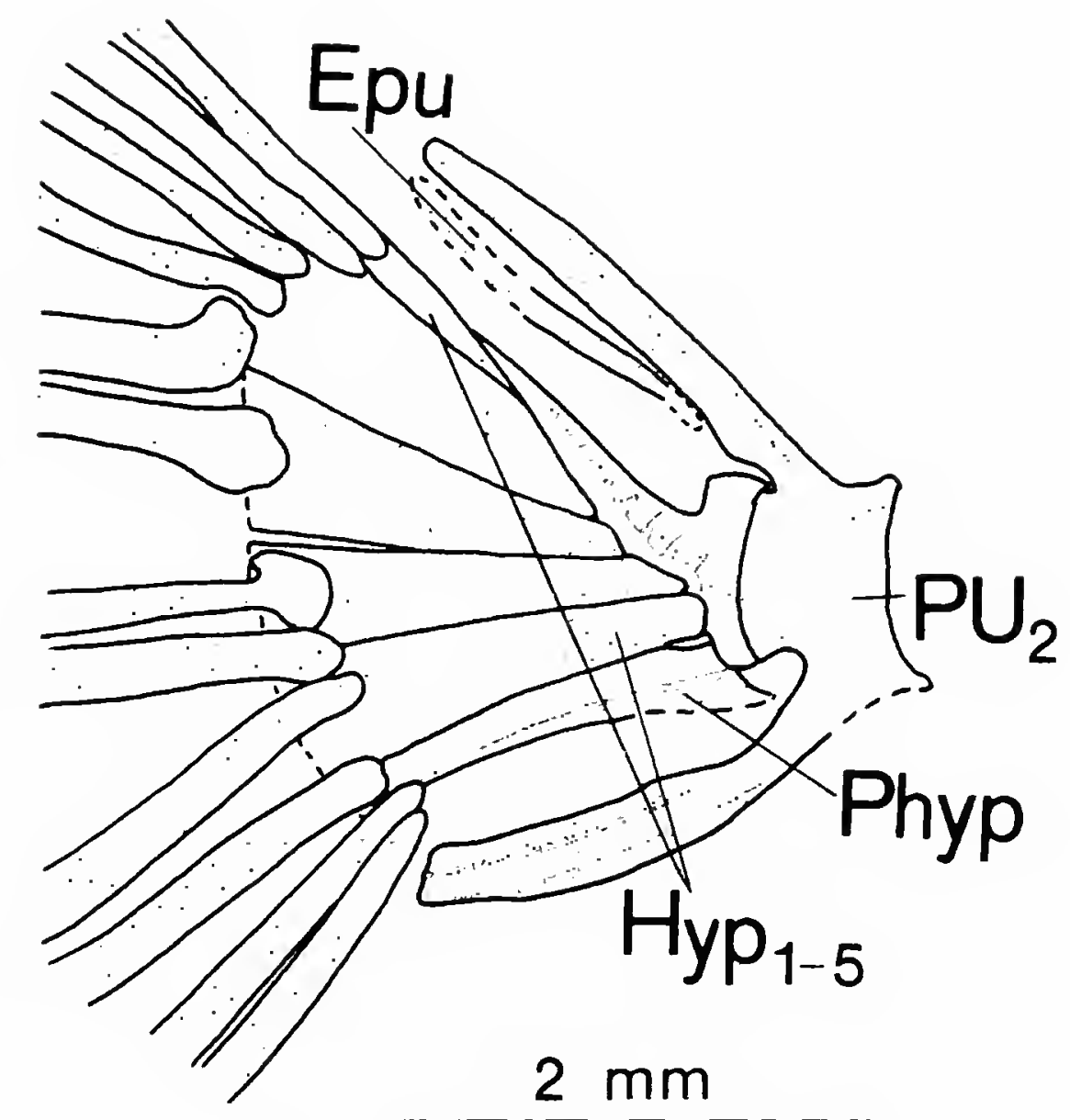

FIGURE 18.-Carpathospinosus propheticus, new genus and species, caudal fin and skeleton, holotype.

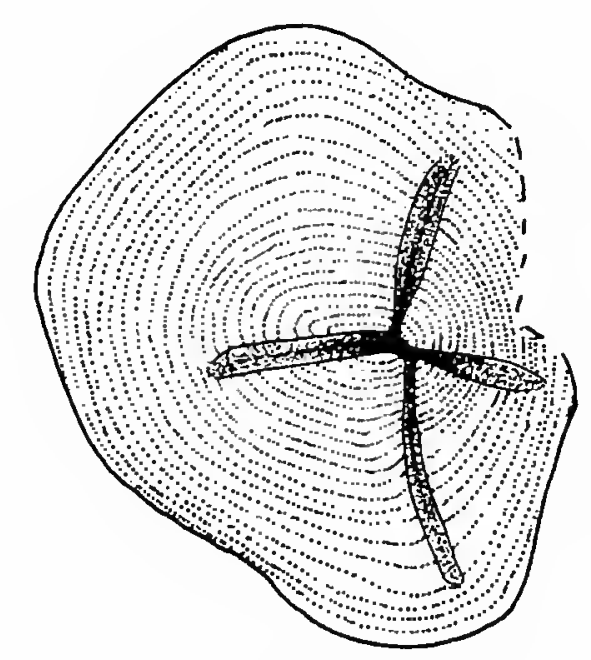

$0.5 \mathrm{~mm}$

FIGURE 19.-Carpathospinosus propheticus, new genus and species, basal plate of scale in dorsolateral view, holotype.

or evolutionary classification (i.e., non-cladistic) of the triacanthoids and other tetraodontiforms, Tyler (1980) placed the Eocene Eoplectus and Zignoichthys as one subfamily (Eoplectinae) and the Eocene Spinacanthus and Protobalistum as another subfamily (Spinacanthinae) of the triacanthodids along with the Recent hollardiins and triacanthodins.

Eoplectus and Zignoichthys were referred to the triacanthodids by Tyler $(1973,1980)$ because of their overall general similarity to that family based on the presence of what are now 
recognized to be numerous plesiomorphic features such as well-developed spiny dorsal and pelvic fins (condition of these uncertain in Zignoichthys). Tyler emphasized that Eoplectus and Zignoichthys represented the ancestral line of tetraodontoids because both genera possess the single most impressive specialized feature of tetraodontoids, the complex and innovative incorporation of the individual tooth elements into the jaw bones of a crushing beak. In Winterbottom's (1974) cladistic analysis of tetraodontiform relationships Eoplectus and Zignoichthys were removed from the triacanthodids and recognized (we believe correctly) as distinct families of tetraodontoids, with the Eoplectidae as the sister group of all other tetraodontoids and the Zignoichthyidae as the sister group at the next higher node on the cladogram (on the presumption that the spiny dorsal fin and pelvis were of reduced size in Zignoichthys).

Spinacanthus and Protobalistum were referred by Tyler $(1968,1980)$ to the triacanthodids mostly on the basis of the enormous spiny dorsal fin and short-based soft dorsal and anal fins. Winterbottom (1974) interpreted the presence of the spiny dorsal fin and the short-based soft fins in these two genera as plesiomorphic features and removed them from the triacanthodids. He placed them as the Spinacanthidae among the balistoids because of the proposed derived nature of an elongate ethmoid region, small eye high in the head, and forward position of the spiny dorsal-fin origin. The spinacanthids (both genera based on single specimens) are known almost exclusively on the basis of external features, with the condition of the pelvis and pelvic fin unknown. Until more specimens of these two genera with some of their osteology exposed become available, we accept their placement among the balistoids on the basis of the few derived external features of similarity between the groups. The poorly resolved familial relationships of spinacanthids are discussed by Tyler and Bannikov (1992) in relation to the enigmatic Eocene balistoid Eospinus.

The Oligocene Cryptobalistes is poorly known (the single species based on three impressions, a holotype in counterpart and a single plate paratype). The general external countenance and osteological features are in many ways intermediate between triacanthids and balistids. For these reasons they were placed by Tyler $(1968,1980)$ as a subfamily (Cryptobalistinae) of the triacanthids. Winterbottom (1974), however, pointed out that one clearly apomorphic feature of Cryptobalistes was its basin-like pelvis, similar to that of triacanthodins. Therefore, he removed Cryptobalistes from the triacanthids and placed it questionably as a subfamily of the triacanthodids. A more definitive phylogenetic placement of Cryptobalistes awaits additional specimens with well-exposed internal characters.

The better-preserved holotypic counterpart plate on which most of the original description and illustrations of Cryptobalistes are based cannot be located despite many efforts by Winterbottom (1974:96), Tyler (1980:98), and us more recently. It was probably destroyed during World War II after having been transferred from Bonn to the Cologne Natural
History Museum. Hans-Dieter Sues (pers. comm.) searched the Bonn collections for us and found two single plates of the species, both faint impressions, one of which may be the paratype, and the other probably not a type specimen. Dr. Sues prepared the latter specimen for us by powered glass air abrasion but it does not show any of the critically important osteological features (e.g., the shapes of the pelvis and supraoccipital) that would permit us to resolve its relationships. Thus, Cryptobalistes as presently known cannot shed light on the analysis of the relationships of the two new Oligocene genera of triacanthodids.

The earliest known tetraodontiform, Plectocretacicus (Sorbini, 1979), from the upper Cretaceous of Lebanon, has not yet had its familial relationship thoroughly analyzed but it was tentatively placed among the aracanid-ostraciid clade of balistoids and its relationships do not seem to be germane to the present work.

\section{Discussion of SubfamiLial DEFINING CHARACTERS}

The description of a new Oligocene genus in each of the two subfamilies of triacanthodids that otherwise consist of Recent species calls for the determination of which of the five major differential features that have been used (Tyler, 1968, 1980) to phenetically define the subfamilies are primitive versus derived. Establishment of the polarity of the shaft-like versus basin-like posterior process of the pelvis, the meeting of the epiotics medially on the dorsal surface of the skull versus their being excluded from the dorsal surface by the supraoccipital, the articulation anteriorly of the epiotics with the frontals versus the sphenotics, the dome-shaped versus flat supraoccipital, and the presence versus absence of an anteromedial flange on the first basal pterygiophore of the anal fin is critical to an understanding not only of the phylogeny of the triacanthodids but also of the triacanthids that together form the sistergroup of all other tetraodontiforms.

To polarize these features we accept the Triacanthodidae (and its two subfamilies, the Hollardiinae and Triacanthodinae) as the sistergroup of the Triacanthidae, those two families (the triacanthoids) as the sistergroup of all other Tetraodontiformes (the balistoids and tetraodontoids) as proposed in the ordinal phylogeny of Winterbottom (1974, but recognizing the familial systematic levels of Tyler, 1980). We likewise accept the Zeiformes (excluding caproids) as the extraordinal outgroup for the Tetraodontiformes (Rosen, 1984).

Thus, in our analyses of relationships we treat hollardiins and triacanthodins as sistergroups for which triacanthids are the first outgroup (1 o.g.). All other tetraodontiforms are the sister group of the triacanthoids and therefore the second outgroup (2 o.g.). However, because the balistoid and tetraodontoid lineages among the second outgroup are so anatomically distinctive, we frequently discuss the conditions in balistoids (balistids and monacanthids, and their sister group composed of aracanids and ostraciids) separately (as $2 \mathrm{a}$ o.g.) from those of tetraodontoids (as $2 \mathrm{~b}$ o.g., the clade based on the anatomically 


\section{Superfamily Triacanthoidea (triacanthoids)}

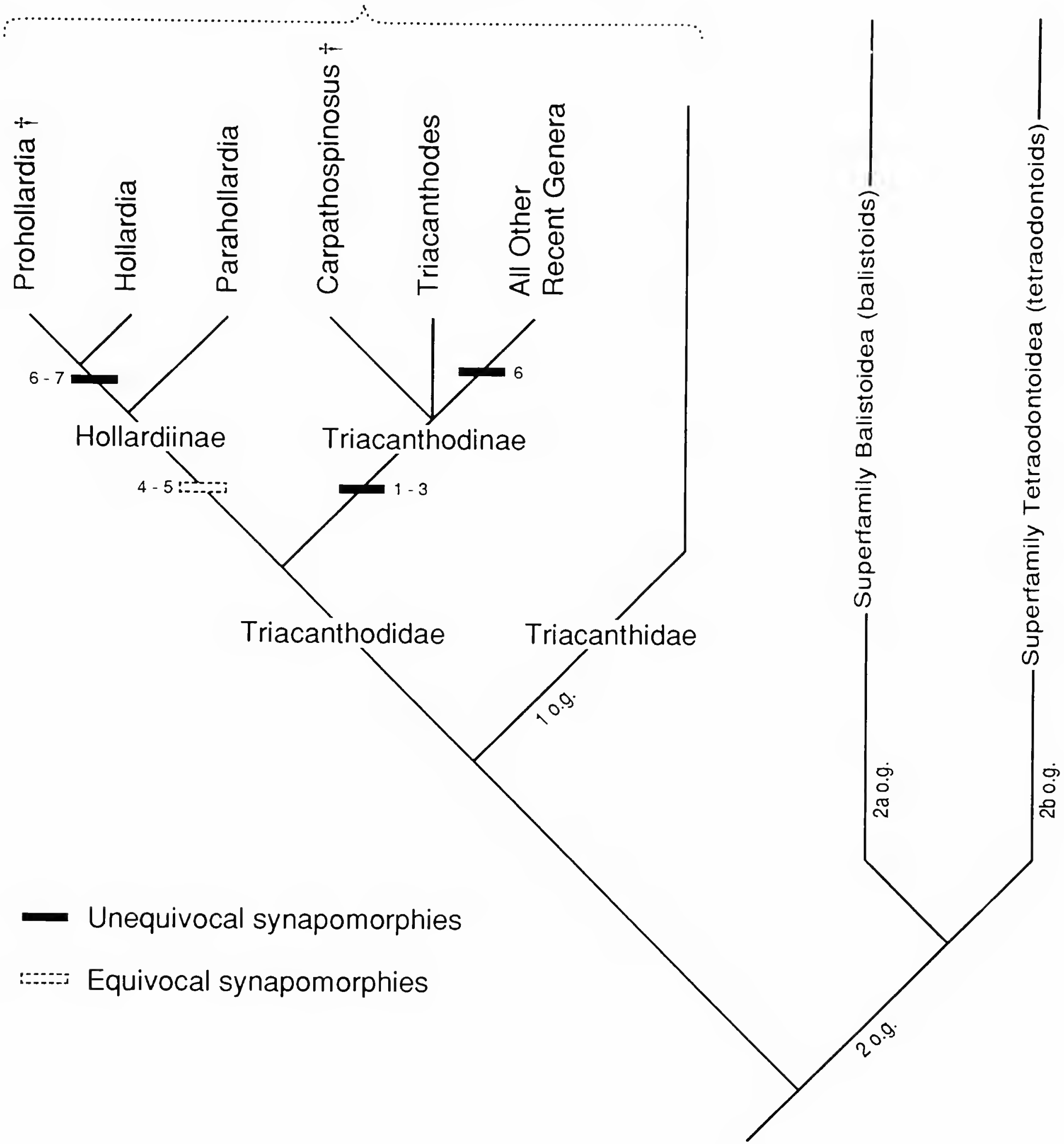

FIGURE 20.-Cladogram of relationships of the two new Oligocene genera of Triacanthodidae (relationships of other families based largely on Winterbottom, 1974). Unequivocal synapomorphies are: 1, posterior process of pelvis basin-like; 2 , epiotics meeting medially on dorsal surface of skull; 3, epiotics separated from frontals by sphenotics; 6 , inner series teeth absent; 7, scales present on spiny dorsal-fin membranes. Equivocal synapomorphies are: 4 , supraoccipital dome-like; 5 , first anal-fin basal pterygiophore flange present. See text for discussion of each of these features used to establish relationships of the fossils within the family.

generalized Eocene eoplectids, which also includes triodontids, zignoichthyids, tetraodontids, diodontids, and molids). These relationships are summarized in Figure 20.
In the following analysis it is necessary to keep in mind the distinction between the names of the triacanthodids (Triacanthodidae) and its subfamilies, the triacanthodins (Triacantho- 
TABLE 3.-Major differences and similarities of Prohollardia. Carpathospinosus, the Recent Hollardiinae, and the Recent Triacanthodinae with typical snout lengths (i.e., excluding the two genera with extremely elongate tubular snouts, Macrorhamphosodes and Halimochirurgus); data for Recent species from Tyler (1968).

\begin{tabular}{|c|c|c|c|c|}
\hline Character & Prohollardia & $\begin{array}{c}\text { Recent } \\
\text { Hollardiinae } \\
\end{array}$ & Carpathospinosus & $\begin{array}{c}\text { Recent Triacanthodinae } \\
\text { with typical snouts }\end{array}$ \\
\hline $\begin{array}{l}\text { Shape of posterior process of } \\
\text { pelvis }\end{array}$ & shaft-like & shaft-like & basin-like & basin-like \\
\hline $\begin{array}{l}\text { Relationship of epiotics to one } \\
\text { another }\end{array}$ & $\begin{array}{l}\text { do not meet one another } \\
\text { medially on dorsal sur- } \\
\text { face of skull, separated } \\
\text { by supraoccipital }\end{array}$ & $\begin{array}{l}\text { do not meet one another } \\
\text { medially on dorsal sur- } \\
\text { face of skull, separated } \\
\text { by supraoccipital }\end{array}$ & $\begin{array}{l}\text { meet one another medially } \\
\text { on dorsal surface of } \\
\text { skull, not separated } \\
\text { there by supraoccipital }\end{array}$ & $\begin{array}{l}\text { meet one another medially } \\
\text { on dorsal surface of } \\
\text { skull, not separated } \\
\text { there by supraoccipital }\end{array}$ \\
\hline $\begin{array}{l}\text { Relationship of epiotics to } \\
\text { frontals }\end{array}$ & $\begin{array}{l}\text { articulate anteriorly } \\
\text { with frontals }\end{array}$ & $\begin{array}{l}\text { articulate anteriorly } \\
\text { with frontals }\end{array}$ & $\begin{array}{l}\text { separated from frontals by } \\
\text { sphenotics }\end{array}$ & $\begin{array}{l}\text { separated from frontals by } \\
\text { sphenotics }\end{array}$ \\
\hline Shape of supraoccipital & dome-like & dome-like & $\begin{array}{l}\text { broad and flat, with me- } \\
\text { dial crest }\end{array}$ & $\begin{array}{l}\text { broad and flat, with me- } \\
\text { dial crest }\end{array}$ \\
\hline $\begin{array}{l}\text { Anteromedial flange on distal } \\
\text { region of first anal-fin basal } \\
\text { pterygiophore }\end{array}$ & unknown & present & present & absent \\
\hline $\begin{array}{l}\text { Teeth internal to major outer } \\
\text { series }\end{array}$ & absent & $\begin{array}{l}\text { present (Parahollardia) } \\
\text { or absent (Hollardia) }\end{array}$ & unknown & $\begin{array}{l}\text { present (Triacanthodes) } \\
\text { or absent (all other gen- } \\
\text { era) }\end{array}$ \\
\hline $\begin{array}{l}\text { Scales on spiny dorsal-fin } \\
\text { membranes }\end{array}$ & $\begin{array}{l}\text { many, with extensive cov- } \\
\text { erage }\end{array}$ & $\begin{array}{l}\text { some to many, with mod- } \\
\text { erate coverage (Hollar- } \\
\text { dia) or absent (Parahol- } \\
\text { lardia) }\end{array}$ & absent & $\begin{array}{l}\text { absent (except some in } \\
\text { Johnsonina) }\end{array}$ \\
\hline $\begin{array}{l}\text { Origin of spiny dorsal fin in } \\
\text { relation to gill opening }\end{array}$ & distinctly in front & $\begin{array}{l}\text { over or slightly in front } \\
\text { (Parahollardia) or dis- } \\
\text { tinctly behind ( } \mathrm{Hol} \text { - } \\
\text { lardia) }\end{array}$ & distinctly behind & $\begin{array}{l}\text { usually over, sometimes } \\
\text { slightly behind, but dis- } \\
\text { tinctly in front in } \mathrm{Me} \text { - } \\
\text { phisto }\end{array}$ \\
\hline $\begin{array}{l}\text { Inclination of last basal } \\
\text { pterygiophore of spiny dor- } \\
\text { sal fin }\end{array}$ & vertically & anteroventrally & anteroventrally & anteroventrally \\
\hline $\begin{array}{l}\text { Inclination of basal pterygio- } \\
\text { phores of soft dorsal fin }\end{array}$ & first two vertically & all anteroventrally & all anteroventrally & all anteroventrally \\
\hline $\begin{array}{l}\text { Enlarged scale plate with spine } \\
\text { over eye }\end{array}$ & present & absent & absent & absent \\
\hline Inclination of hyomandibular & almost vertical & oblique & probably oblique & oblique \\
\hline $\begin{array}{l}\text { Coverage of first dorsal-fin } \\
\text { and pelvic spines with spin- } \\
\text { ulose scales }\end{array}$ & $\begin{array}{l}\text { only extreme distal tip } \\
\text { naked }\end{array}$ & $\begin{array}{l}\text { distal } 1 / 10 \text { to only extreme } \\
\text { distal tip naked }\end{array}$ & distal $2 / 3-1 / 2$ naked & distal $1 / 2-1 / 10$ naked \\
\hline $\begin{array}{l}\text { Length of spiny dorsal-fin base } \\
\text { relative to soft dorsal-fin base }\end{array}$ & slightly shorter & longer than & longer than & longer than \\
\hline $\begin{array}{l}\text { First dorsal-fin spine when un- } \\
\text { erected reaching posteriorly to: }\end{array}$ & $\begin{array}{l}\text { slightly beyond soft dor- } \\
\text { sal-fin origin to level of } \\
\text { about third ray }\end{array}$ & $\begin{array}{l}\text { in front of or to origin or } \\
\text { slightly beyond origin } \\
\text { of soft dorsal fin (to } \\
\text { level of about second or } \\
\text { third ray) }\end{array}$ & $\begin{array}{l}\text { well beyond soft dorsal- } \\
\text { fin origin to level of } \\
\text { about eleventh ray }\end{array}$ & $\begin{array}{l}\text { in front of or to origin, or } \\
\text { moderately beyond ori- } \\
\text { gin of soft dorsal fin (to } \\
\text { level of about third or } \\
\text { fourth ray) }\end{array}$ \\
\hline Number of dorsal-fin rays & 19 & $15-18(\bar{x}=16-17)$ & 15 & $13-16(\bar{x}=14-16)$ \\
\hline Number of anal-fin rays & 15 & $13-16(\bar{x}=14-15)$ & 12 & $11-14(\bar{x}=12-14)$ \\
\hline Head length as \% SL & $\begin{array}{r}48.0 \%-52.4 \% \\
(\bar{x}=49.5)\end{array}$ & $\begin{array}{l}33.7 \%-44.7 \% \\
\quad(\bar{x}=38-40)\end{array}$ & $45.5 \%$ & $\begin{array}{l}33.1 \%-44.7 \% \\
(\bar{x}=35-41)\end{array}$ \\
\hline Body depth as \% SL & $\begin{array}{r}70.0 \%-72.0 \% \\
(\bar{x}=71.2)\end{array}$ & $\begin{array}{l}40.0 \%-73.4 \% \\
\quad(\bar{x}=51-66)\end{array}$ & $50.0 \%$ & $\begin{array}{l}28.9 \%-66.8 \% \\
\quad(\bar{x}=31-53)\end{array}$ \\
\hline
\end{tabular}


TABLE 3.-Continued.

\begin{tabular}{|c|c|c|c|c|}
\hline Character & Prohollardia & $\begin{array}{c}\text { Recent } \\
\text { Hollardiinae }\end{array}$ & Carpathospinosus & $\begin{array}{l}\text { Recent Triacanthodinae } \\
\text { with typical snouts }\end{array}$ \\
\hline Predorsal length as \% SL & $\begin{array}{r}55.7 \%-60.0 \% \\
(\bar{x}=57.5)\end{array}$ & $\begin{array}{l}44.9 \%-65.1 \% \\
(\bar{x}=46-59)\end{array}$ & $\begin{array}{r}50.0 \%-52.3 \% \\
(\bar{x}=51.2)\end{array}$ & $\begin{array}{l}33.7 \%-54.1 \% \\
\quad(\bar{x}=36-48)\end{array}$ \\
\hline $\begin{array}{l}\text { Length of first dorsal spine as } \\
\% \mathrm{SL}\end{array}$ & $\begin{array}{r}20.7 \%-28.1 \% \\
(\bar{x}=24.4)\end{array}$ & $\begin{array}{l}17.2 \%-37.9 \% \\
(\bar{x}=24-32)\end{array}$ & $\begin{array}{r}34.8 \%-38.9 \% \\
(\bar{x}=36.9)\end{array}$ & $\begin{array}{l}18.6 \%-37.3 \% \\
\quad(\bar{x}=21-34)\end{array}$ \\
\hline $\begin{array}{l}\text { Length of second dorsal spine } \\
\text { as \% SL }\end{array}$ & $\begin{array}{r}13.0 \%-14.1 \% \\
(\bar{x}=13.4)\end{array}$ & $\begin{array}{l}12.9 \%-33.6 \% \\
(\bar{x}=18-29)\end{array}$ & $\begin{array}{r}14.8 \%-15.8 \% \\
(\bar{x}=15.3)\end{array}$ & $\begin{array}{l}13.1 \%-31.5 \% \\
(\bar{x}=15-29)\end{array}$ \\
\hline $\begin{array}{l}\text { Length of second dorsal spine } \\
\text { into that of first dorsal spine }\end{array}$ & $1.6-2.0 \times(\bar{x}=1.8)$ & $1.0-1.3 \times(\bar{x}=1.1-1.3)$ & $2.4-2.5 \times(\bar{x}=2.4)$ & $1.0-1.4 \times(\bar{x}=1.2-1.4)$ \\
\hline Soft dorsal-fin height as \% SL & $23.0 \%$ & $\begin{array}{l}12.1 \%-20.4 \% \\
(\bar{x}=14-18)\end{array}$ & $-16 \%$ & $\begin{array}{l}11.4 \%-19.8 \% \\
(\bar{x}=13-19)\end{array}$ \\
\hline Spiny dorsal-fin base as \% SL & $\begin{array}{r}19.2 \%-23.6 \% \\
(\bar{x}=21.4)\end{array}$ & $27 \%-30 \%$ & $26.9 \%$ & $26 \%-32 \%$ \\
\hline Soft dorsal-fin base as \% SL & $\begin{array}{r}23.0 \%-26.1 \% \\
(\bar{x}=24.6)\end{array}$ & $18 \%-22 \%$ & $15.2 \%$ & $16 \%-21 \%$ \\
\hline $\begin{array}{l}\text { Spiny dorsal-fin base in rela- } \\
\text { tion to soft dorsal-fin base }\end{array}$ & $\begin{array}{l}\text { shorter by } 2.5 \%-3.8 \% \mathrm{SL} \\
\quad(\overline{\mathrm{x}}=3.2 \%)\end{array}$ & longer by $5 \%-12 \%$ SL & longer by $11.7 \% \mathrm{SL}$ & longer by $10 \%-14 \% \mathrm{SL}$ \\
\hline $\begin{array}{l}\text { Length of posterior process of } \\
\text { pelvis as } \% \mathrm{SL}\end{array}$ & $\begin{array}{r}14.5 \%-21.4 \% \\
(\bar{x}=18.0)\end{array}$ & $\begin{array}{l}16.3 \%-32.2 \% \\
\quad(\bar{x}=24-30)\end{array}$ & $25.4 \%$ & $\begin{array}{l}21.7 \%-39.4 \% \\
(\bar{x}=28-34)\end{array}$ \\
\hline $\begin{array}{l}\text { Width of posterior process of } \\
\text { pelvis as \% SL }\end{array}$ & $6.7 \%$ & $2.6 \%-8.4 \%(\bar{x}=4-6)$ & $13.1 \%$ & $\begin{array}{l}5.3 \%-17.8 \%(\bar{x}=6- \\
18)\end{array}$ \\
\hline $\begin{array}{l}\text { Posterior process of pelvis width } \\
\text { into length }\end{array}$ & $3.2 \times$ & $3.2-9.3 \times(\bar{x}=4-7)$ & $1.9 \times$ & $1.9-5.8 \times(\bar{x}=2-5)$ \\
\hline Length of pelvic spine as \% SL & $\begin{array}{r}19.0 \%-30.1 \% \\
(\bar{x}=24.6)\end{array}$ & $\begin{array}{l}14.7 \%-34.3 \% \\
\quad(\bar{x}=23-30)\end{array}$ & $38.9 \%$ & $\begin{array}{l}18.8 \%-42.4 \% \\
\quad(\bar{x}=25-36)\end{array}$ \\
\hline $\begin{array}{l}\text { Length of posterior process of } \\
\text { pelvis into length of pelvic spine }\end{array}$ & $1.3-1.4 \times(\bar{x}=1.4)$ & $0.9-1.0 \times(\bar{x}=1.0)$ & $1.5 \times$ & $0.8-1.1 \times(\bar{x}=1.0)$ \\
\hline
\end{tabular}

dinae) and hollardiins (Hollardiinae), and the triacanthids (Triacanthidae).

PELVIS (Character 1).- The posterior process is shaft-like in hollardiins, with the halves from either side closely articulated or fully consolidated with one another along their medial edges to form a stout rod, flattish to slightly concave dorsally and rounded to ridged ( $\mathrm{U}$ - to $\mathrm{V}$-shaped in cross-section) ventrally. In triacanthodins the two halves of the process are dorsoventrally flattened, situated in the horizontal plane, and articulated with one another medially, while their lateral portions are upturned, thus forming a broad basin of varying widths (for widths see section on "Relationships of Carpathospinosus in Triacanthodinae" and Table 3).

In triacanthids ( 1 o.g.) the process is a sturdy shaft, with the two halves fused or extensively sutured together to form a solid bone like a railroad rail in cross-section, in what we interpret as a more solidified version of the shaft-like process of hollardiins.

In balistoids ( $2 \mathrm{a}$ o.g.) the entire pelvis usually (i.e., in all but a few highly specialized monacanthids in which the pelvis is secondarily somewhat reduced; pelvis absent in aracanids and ostraciids) is a long strong shaft in which the two halves are indistinguishably fused together in the midline. The balistoid condition differs from that of hollardiins and triacanthids mainly in having rudimentary pelvic spine elements at its posterior end rather than large spines with a locking mechanism midway along its length. The balistoid pelvis has some additional specializations, including a posterodorsal lobe and concave anterolateral surfaces associated with the rotation of the pelvis around its cleithral attachment which permits balistoids to flare a dewlap between the end of the pelvis and the anus.

In tetraodontoids ( $2 \mathrm{~b}$ o.g.) a pelv is is present only in the two most morphologically primitive families. In the Eocene eoplectids there is a pelvic fin but the structure of the pelvis is unknown. In triodontids there is a pelvis but no pelvic fin. The posterior half of the pelvis is shaft-like, with the two halves closely articulated to one another medially and, in larger specimens, partially fused. The ascending process is deeply concave to accommodate the muscles that rotate the pelvis in flaring a huge dewlap of abdominal skin (comparable to that of balistoids). 
Because the posterior process is basin-like only in triacanthodins and shaft-like in its sistergroup (hollardiins) and in all of the tetraodontiform outgroups, it is hypothesized that the shaft-like condition is plesiomorphic and that the basin-like condition is a synapomorphy of triacanthodins.

It is noteworthy that some zeids among the zeiform extraordinal outgroup have a pelvis with a posterior process comparable to the shaft-like plesiomorphic condition of the bone in tetraodontiforms. In Zeus and Zenopsis each half of the pelvis has a sturdy shaft-like process which is rounded in cross-section and slightly separated from its opposite member along the midline of the belly. The average length of the process is $11 \% \mathrm{SL}$ in Zeus faber (including the Oligocene specimen illustrated by Świdnicki, 1986:111, fig. 1) and $16 \%-22 \%$ in the three examined species of Zenopsis. If these paired processes were closely articulated to one another in the midline the combined sturdy shaft would be similar to that of hollardiins, and, in the case of Zenopsis, almost as long as that in hollardiins (averages $24 \%-30 \%$ SL). Some other zeids (Cyttus and Capromimus) have paired processes that are more or less shaft-like while others (Cyttopsis and Stethopristes) have processes that are short, flat, paired plates oriented obliquely dorsolaterally to ventromedially, a very different configuration than that of Zeus and Zenopsis.

In other zeiform families (parazenids, grammicolepidids, oreosomatids, and macrurocyttids) there is much variation in the shape of the posterior processes but they are basically flattened and oblique rather than shaft-like.

The tapering posterior paired processes of some zeids apparently are homoplastic to the thicker consolidated shaftlike structures in hollardiins, given the large number of derived features uniting the tetraodontiforms.

Position OF EPIOTICS ON DORSAL SURFACE OF SKULL (Character 2).-The epiotics do not meet medially on the dorsal surface of the skull in hollardiins, being separated there by the supraoccipital. In triacanthodins, by contrast, the medial edges of the epiotics are broadly in contact on the dorsal surface of the skull behind the supraoccipital (Tyler, 1968, fig. 4). In triacanthids, balistoids, tetraodontoids ( $1-2$ o.g. $)$, and the zeiform extraordinal outgroup the epiotics are separated by the supraoccipital on the dorsal surface of the skull as in hollardiins. Such separation therefore is hypothesized to be the plesiomorphic condition for tetraodontiforms. The triacanthodin condition of the epiotics meeting medially on the dorsal surface behind the supraoccipital consequently is considered derived.

EPIOTIC ANTERIOR ARTICULATION (Character 3).--In hollardiins the epiotics articulate anteriorly with the frontals while in triacanthodins the epiotics and frontals are separated by the sphenotics. In triacanthids and balistoids ( $1-2 \mathrm{a}$ o.g.) the epiotics contact the frontals. Among tetraodontoids ( $2 \mathrm{~b}$ o.g.) the epiotics articulate with the frontals in the morphologically primitive triodontids and in molids and nearly all tetraodontids. However, in a few specialized tetraodontids (e.g., Chonerhinos,
Xenopterus, Carinotetraodon) and in all diodontids the epiotics are separated from the frontals by the sphenotics, somewhat comparably to the condition in triacanthodins.

In the zeiform extraordinal outgroup the epiotics are separated from the frontals by the parietals, a bone not present in tetraodontiforms. Thus, the separation of the epiotics and frontals in zeiforms by the parietals is not homologous with the condition in triacanthodins, diodontids, and some tetraodontids in which the two bones are separated by the sphenotics.

Based on outgroup comparisons the separation of the frontals and epiotics in triacanthodins is derived. A hypothesis that the condition of the epiotics articulating with the frontals is plesiomorphic for tetraodontiforms requires three steps to account for the independent acquisition of separation of the epiotic and frontal in triacanthodins, diodontids and some tetraodontids. The contrasting hypothesis of the separation of the epiotics by the sphenotics being plesiomorphic would require six steps (independent acquisition by hollardiins, triacanthids, balistids-ostraciids, triodontids, some tetraodontids, and molids) to account for the distribution of the epiotic-frontal articulation character in the majority of groups of tetraodontiforms. Likewise, epiotic articulation with the frontal is primitive for the triacanthoid clade, requiring only one step for acquisition of epiotic separation by the sphenotics (versus two if epiotic separation were hypothesized as primitive) and this is evidence of triacanthodin monophyly.

SUPRAOCCIPITAL (Character 4).-The supraoccipital in hollardiins is dome-like, without a broad flat expanse. In triacanthodins the supraoccipital is flat, with a broad flat expanse and a small crest or dome anteromedially.

In triacanthids $(1$ o.g. $)$ the structure of the posterodorsal region of the skull is similar to that of hollardiins, for the supraoccipital is dome-like, without a broad flat expanse. The main difference between the dome-like structure in hollardiins and triacanthids is that the posterior surface of the dome is convex in the former and concave in the latter.

In balistoids ( $2 \mathrm{a}$ o.g.) the supraoccipital in the balistidmonacanthid clade is flat, with a high medial crest and posterior buttress in balistids for support of the highly specialized, enlarged, and forward migrated first basal pterygiophore of the spiny dorsal fin (the carina). In the aracanid-ostraciid clade of balistoids the supraoccipital is similarly flat, but without any buttressing since the spiny dorsal fin is absent.

In tetraodontoids ( $2 \mathrm{~b}$ o.g.) the supraoccipital is relatively flat and has a well-developed low flange projecting posteriorly in triodontids, tetraodontids, and diodontids. In molids, however, the supraoccipital is more dome-like. Nevertheless, numerous specialized features unite the molids with the other tetraodontoids (Winterbottom, 1974; Tyler, 1980). Thus, the dome-like supraoccipital in molids must be considered to have been acquired independently of that in triacanthoids under the overall most parsimonious scheme of relationships.

The hypothesis of a flat supraoccipital being primitive for tetraodontiforms is in accord with the condition in the zeiform 
extraordinal outgroup, in which the supraoccipital is always relatively broad and flat, with a low to high medial crest.

While a flat supraoccipital is hypothesized to be primitive for tetraodontiforms, there are two equally parsimonious explanations for the distribution of the dome-like supraoccipital in triacanthoids. Either the flat supraoccipital is the ancestral condition for the triacanthoid clade and the dome-like condition has been acquired independently by hollardiins and triacanthids, or the apomorphic dome-like condition arose in the ancestor of the triacanthoid clade and was lost secondarily by triacanthodins (two steps in either case).

Thus, if the ancestral triacanthoid had a flat supraoccipital like zeiforms and balistoids (and most tetraodontoids) then the dome-like supraoccipital would be a synapomorphy of hollardiins. Although equivocal, we favor this hypothesis and consider the dome-like supraoccipital as an ambiguous synapomorphy of hollardiins. Conversely, if the ancestral triacanthoid had a dome-like supraoccipital then the simpler dome with a convex posterior surface as found in hollardiins could be considered primitive because the central elevation of the relatively round, flat plate of the ancestral tetraodontiform supraoccipital presumedly would result in a conical structure rather than one with a triacanthid-like concave posterior surface. The condition of the triacanthid supraoccipital is therefore hypothesized to be derived under this scenario.

Another hypothesis, that the configuration of the supraoccipital-epiotic region is a synapomorphy that indicates triacanthodins are the sistergroup of hollardiins and triacanthids is not parsimonious when other evidence is considered. The seven myological synapomorphies given in Winterbottom (1974), and presumedly many of the specialized osteological character states for triacanthoids given in Tyler (1980), support the hypothesis of a sistergroup relationship between triacanthodids and triacanthids rather than between hollardiins and triacanthids.

FIRST BASAL PTERYGIOPHORE OF ANAL Fin (Character 5).- The first anal-fin basal pterygiophore in hollardiins has a prominent anteromedial flange along the lower portion of its length in Hollardia and, to a lesser extant, in Parahollardia. As a consequence, the pterygiophore is " + " shaped in crosssection. In Recent triacanthodins and in triacanthids, balistoids, and tetraodontoids (1-2 o.g.) this anteromedial flange is absent and the pterygiophore is T-shaped in cross-section. The absence of the flange is therefore judged to be the plesiomorphic condition for tetraodontiforms.

As with supraoccipital shape, we can only note that, given the distribution of the presence of the flange, the possession of the flange is a possible synapomorphy of hollardiins under one of the two equally parsimonious hypotheses. Under that scenario the absence of the flange also is a possible synapomorphy of all Recent triacanthodins to the exclusion of Carpathospinosus.

It is noteworthy that in the zeiform extraordinal outgroup the first anal-fin basal pterygiophore sometimes has a low thick crest along its lower anterior edge, especially in zeids. Under the overall most parsimonious scheme of higher level relationships noted above, this crest in some zeiforms is hypothesized as homoplastic to the thinner flange on the first anal-fin basal pterygiophore in triacanthodids.

The presence of an anteromedial flange in one of the new Oligocene genera, Carpathospinosus (which has three synapomorphies uniting it with triacanthodins), requires reassessment of its significance. Rather than being a potentially unequivocal diagnostic synapomorphy of hollardiins, the presence of the flange also in Carpathospinosus can be explained equally parsimoniously by the flange having arisen in the ancestor of the triacanthodid clade and been lost by the ancestor of Recent triacanthodins or that the ancestral triacanthodid lacked the flange which was acquired independently by hollardiins and Carpathospinosus (two steps in either case).

SUmmary OF SubFamilial Characters of New TaXa.Three of the five contrasting character states (shape of posterior process of pelvis, position of epiotic on posterodorsal region of skull, and anterior articulation of epiotic) that are used to diagnose the two subfamilies of triacanthodids can be unequivocally polarized and for all three the derived condition (basin-like process, epiotics meeting medially on dorsal surface of skull, and epiotics separated from frontals by sphenotic) is found in triacanthodins (including the Oligocene Carpathospinosus). The other two characteristics (supraoccipital shape and form of anteromedial edge of first basal pterygiophore of anal fin) are equivocal but the conditions (supraoccipital dome-like and anteromedial flange on pterygiophore present) found in hollardiins (including the Oligocene Prohollardia) could be derived under one of two alternate scenarios for each feature.

Thus, we have been able to establish the monophyly of triacanthodins but not unequivocally so that of hollardiins.

\section{RELATIONSHIPS OF Prohollardia IN HOLLARDIINAE}

The two Recent genera of hollardiins are distinguished by several features (Tyler, 1968:68, 73, 93). Parahollardia has one to ten (usually two to four) teeth internal to the outer series in each jaw, the origin of the spiny dorsal fin usually slightly in front of the vertical through a line along the upper edge of the gill opening, and the scales of large adults with numerous, finely branched upright spinules. Hollardia has no inner series teeth, the spiny dorsal origin slightly to distinctly behind the level of the gill opening, and the scales of large adults with relatively few and course branches of the spinules.

Prohollardia lacks inner series teeth and the position of the origin of the spiny dorsal fin is distinctly anterior to the level of the gill opening. All of the specimens of Prohollardia are relatively small and comparison cannot be made to the differential spinule conditions that develop only in large specimens of the other two genera, small specimens of which have spinules like those of Prohollardia. 
Of the tooth and spiny dorsal-fin origin differences of the two Recent genera, for which there are comparable data for Prohollardia, the former is phylogenetically informative but the latter is difficult to polarize because of pronounced variability in the position of fin origin in the sister group and outgroups.

For example, in triacanthodins the spiny dorsal-fin origin varies from over or only slightly in front of or behind the gill opening to substantially behind it (e.g., Macrorhamphosodes) or substantially in front of it (Mephisto). In triacanthids (1 o.g) the origin is slightly to distinctly behind the gill opening, while in balistoids ( $2 \mathrm{a}$ o.g. ) the origin is over or distinctly behind the gill opening in balistids but over to well in front of it in the derived monacanthids (spiny dorsal fin absent in the derived aracanid-ostraciid clade). In tetraodontoids ( $2 \mathrm{~b}$ o.g.) the spiny dorsal fin usually is absent but when present in the Eocene eoplectids its origin is well behind the gill opening and when present as a rudiment in triodontids its origin is far behind the gill opening. In the zeiform extraordinal outgroup the spiny dorsal-fin origin is well behind the gill opening (i.e., anterior edge of cleithrum).

Because the spiny dorsal-fin origin is slightly to well behind the gill opening in triacanthids, morphologically primitive balistoids, eoplectids, and triodontids, we consider this the plesiomorphic condition. Therefore, the far anterior position of the origin in Prohollardia is hypothesized simply as an autapomorphy within hollardiins, and independent of that found in Mephisto alone among triacanthodins.

SYNAPOMORPHIES OF Prohollardia AND Hollardia.Among triacanthodids inner series teeth are present only in one Recent genus (Parahollardia) of hollardiins and in one Recent genus (Triacanthodes) of triacanthodins. All triacanthids (l o.g.) have inner series teeth in both the upper and lower jaw. Among balistoids (2a o.g.), the more morphologically primitive members (balistids and monacanthids) have inner series teeth in the upper jaw but these are absent in the lower jaw, while in the more derived members (the aracanid-ostraciid clade) inner teeth are absent in both jaws. Most tetraodontoids ( $2 b$ o.g.) have inner series teeth in the form of a specialized trituration apparatus of a few molariform or laterally elongate teeth or of a massive plate of consolidated teeth. In the zeiform extraordinal outgroup, the dentition usually forms a narrow band several teeth wide. We interpret the zeiform condition as ancestral to that of a major outer row with fewer teeth internal to it. The presence of inner series teeth in the first outgroup and in at least the morphologically primitive members of the second tetraodontiform outgroup, and the ancestral conditions in the zeiform outgroup, leads us to hypothesize that the presence of inner series teeth is plesiomorphic. Therefore, the absence of inner series teeth (Character 6) is hypothesized as a synapomorphy of Prohollardia and Hollardia in the Hollardiinae, and homoplastic to the loss of inner series teeth in all triacanthodins except Triacanthodes.

Only one other character has been found that differs between the three genera of hollardiins which can be polarized with confidence. This feature, involving the scales on the spiny dorsal fin, also indicates a sistergroup relationship between Prohollardia and Hollardia.

The membrane of the spiny dorsal fin is essentially scaleless in all triacanthodins, with the exception of a few scales basally between the second to fourth spines in Johnsonina (Tyler, 1968:158, fig. 53). This membrane is scaleless in triacanthids ( 1 o.g.), in balistoids ( 2 a o.g.) with spiny dorsal fins (balistids and monacanthids), in eoplectids and triodontids that alone among tetraodontoids ( $2 \mathrm{~b}$ o.g.) have a spiny dorsal fin, and in the zeiform extraordinal outgroup. A scaleless interspinous membrane thus is clearly plesiomorphic for tetraodontiforms.

Among hollardiins the interspinous membrane is scaleless in Parahollardia, while in Hollardia there are either a few $(H$. meadi and $H$. goslinei Tyler) to many ( $H$. hollardi) spinulose scales basally on the membranes and in Prohollardia an even more extensive covering of the membranes with scales. Therefore, among hollardiins we consider the presence of interspinous membrane scales (Character 7) as a synapomorphy of Hollardia and Prohollardia, with the extensive covering in Prohollardia autapomorphous. The few interspinous scales present in Johnsonina among the triacanthodins is most parsimoniously interpreted as homoplastic to that in hollardiins.

SIMILARITIES BETWEEN Prohollardia AND OTHER GENERA.-There are a number of other similarities between Prohollardia and one or more species of Hollardia that are suggestive of a relationship between them. For example, there are 19 dorsal-fin rays in Prohollardia and modally 17, but often 18 in Hollardia hollardi, while Hollardia goslinei and $H$. meadi and Parahollardia lineata and P. schmidti Woods have only 16 rays modally. There are 15 anal-fin rays in Prohollardia and $H$. hollardi (modally) but only 14 modally in the other two species of Hollardia and both species of Parahollardia. However, these fin-ray differences are difficult to polarize because of pronounced variability in the outgroups (see Tyler, 1968, 1980 for meristic data).

We note that increased body depth in hollardiins is as variable as the position of the spiny dorsal-fin origin. In triacanthodins the average body depth is $31 \%-53 \%$ SL in the species with typical body shapes (i.e., exclusive of the two long-snouted derived genera with depths of only $16 \%-22 \%$ $\mathrm{SL})$. In triacanthids $(1$ o.g.) the average body depth is $31 \%-45 \%$ SL, and in balistoids (2a o.g.) about $40 \%-50 \%$ SL in most species (but with depth especially wide ranging in the derived monacanthids, from about $12 \%-86 \%$ SL in such genera as, respectively, Psilocephalus and Brachaluteres). Body depth is moderate in most tetraodontoids ( $2 \mathrm{~b}$ o.g.), usually $25 \%-45 \%$ SL (but great in the Eocene eoplectids, $93 \%$ $\mathrm{SL})$. In the zeiform extraordinal outgroup the depth ranges from about $50 \%-55 \% \mathrm{SL}$ in at least the more anatomically generalized members (i.e., zeids).

Therefore, we hypothesize body depths of about $30 \%$ to $55 \%$ 
SL as plesiomorphic for tetraodontiforms. Among hollardiins only Parahollardia schmidti has comparable body depths, $50 \%-60 \% \mathrm{SL}$ in specimens of 30 to $50 \mathrm{~mm} \mathrm{SL}$, versus greater average depths of $65 \%-73 \%$ SL in similarly small specimens of Parahollardia lineata, Hollardia hollardi, and $H$. meadi (no specimens of $H$. goslinei this small are available, but it has as deep a body as in the adults of the other two species of Hollardia) and Prohollardia. It is equally parsimonious to hypothesize that the ancestral hollardiin had moderate body depth like Parahollardia schmidti and increased depth is an independent acquisition of the Prohollardia-Hollardia clade and of Parahollardia lineata, or that the ancestral hollardiin had increased body depth followed by reduction of depth in $P$. schmidti (two steps in either case).

The relatively short length (average $17.9 \% \mathrm{SL}$ ) and great width $(6.7 \% \mathrm{SL})$ of the posterior process of the pelvis in Prohollardia is more similar to the conditions in Hollardia hollardi (average length $24.7 \%$ SL and width $6.2 \% \mathrm{SL}$ ) (and in $H$. meadi for length, average $23.7 \% \mathrm{SL}$; and in $H$. goslinei for width, average $5.9 \% \mathrm{SL}$ ) than to other hollardiins, in which the average length is $27.0 \%-29.8 \%$ SL and width $3.6 \%-4.6 \%$ SL. These proportional differences, however, are difficult to polarize, primarily because neither the triacanthodins nor the zeiform extraordinal outgroup has a comparably solid, medially placed, shaft-like process.

SUMMARY OF RELATIONSHIPS OF Prohollardia.-We are confident that two synapomorphies show the sistergroup relationship within the hollardiins between Prohollardia and Hollardia; the absence of inner series teeth and the presence of scales on the membranes of the spiny dorsal fin. The other numerous similarities between the two genera are either equivocal or not phylogenetically useful.

\section{RELATIONSHIPS OF Carpathospinosus IN TRIACANTHODINAE}

While its many autapomorphies easily distinguish Carpathospinosus from all other triacanthodins, any effort to establish its relationships therein is severely hampered by not knowing whether it possesses inner series teeth and uncertainty about whether the presence of an anteromedial flange on the first anal-fin basal pterygiophore is primitive or derived (see "Discussion of Subfamilial Defining Characters"). We are aware of only one feature that sheds light on its relationships within the subfamily.

The width of the basin-like posterior process of the pelvis is especially great in Carpathospinosus and in one of the Recent genera, Bathyphylax. The basin-like condition is considered a derived feature because it is unique to triacanthodins among tetraodontiforms (except also present in the enigmatic Oligocene Cryptobalistes, previously discussed).

The width of the shaft-like posterior process in hollardiins and in triacanthids $(1$ o.g.) varies from about $2 \%-6 \% \mathrm{SL}$ (average values, here and below). Pelvic widths range from about $6 \%-12 \%$ SL in most triacanthodins with typical heads
(3\%-7\% SL in the two long-snouted genera because of the long head, but pelvic widths not narrow in comparison to at least some of the more generalized triacanthodins). The one exception is Bathyphylax, in which the pelvis is exceptionally wide (about $14 \%$ SL in $B$. bombifrons Myers and $18 \%$ SL in $B$. omen Tyler), as wide as or wider than in Carpathospinosus (13\% SL). The pelvic width into pelvic length ratio is correspondingly lower in Carpathospinosus (1.9) and Bathyphylax (1.9-2.3) than in other triacanthodins (2.8-5.2 in those with typical snouts; as great as 6.1 in the long-snouted genera).

In triacanthodins pelvic widths greater than the $6 \% \mathrm{SL}$ greatest average found in hollardiins and triacanthids must be considered apomorphic, increasingly so with increasing width in an ordered transformation series. The great pelvic width could be interpreted as a synapomorphy of Carpathospinosus and Bathyphylax indicating their sistergroup relationship. However, this argument is somewhat weakened by the fact that two other triacanthodins have pelvises that are only slightly less wide than in Carpathospinosus; the width is between $11 \%$ $12 \% \mathrm{SL}$ and the ratio 2.8-3.0 in the monotypic Mephisto and in one of the two species of Paratriacanthodes, $P$. retrospinis Fowler. Since the differences in pelvic width and the width into length ratio in these various genera, or of one of the species of the genus, are slight, we prefer to simply postulate that Carpathospinosus is probably most closely related among the triacanthodins to the genera with relatively wide pelvises (Bathyphylax, Mephisto, and Paratriacanthodes).

Given the unknown condition of inner dentition in Carpathospinosus, the uncertainty of the interpretation of the anteromedial flange on the first anal-fin basal pterygiophore, and the close approach by several other genera to the great pelvic width in Carpathospinosus and Bathyphylax, we prefer to place Carpathospinosus in an unresolved trichotomy with, on the one hand, Triacanthodes (inner series teeth present and flange absent), and on the other with the clade composed of all of the other Recent triacanthodin genera (inner series teeth and flange absent).

\section{REFERRAL OF Cephalacanthus trispinosus CIOBANU TO TRIACANTHIDAE}

Ciobanu (1977) briefly described a small (29 mm SL) Oligocene fish from Romania in the dactylopteriform family Cephalacanthidae $=$ Dactylopteridae as Cephalacanthus trispinosus. This allocation apparently was based on the resemblance of the large first dorsal and pelvic spines to the massive occipital and preopercular spines in dactylopterids, and perhaps to their elongate but slender dorsal spines. However, the single specimen is described as having numerous soft dorsal (20-22) and anal (16) rays, far more than in dactylopterids, and a pectoral fin of normal size, whereas the pectoral is always enormously elongate in dactylopterids. There is no mention in the description or evidence in the illustration of enlarged scales 
and bony plates such as those that cover the body of dactylopterids.

The illustration of Cephalacanthus trispinosus shows a fish that is strikingly similar to a young triplespine of the tetraodontiform family Triacanthidae, and especially to the two species of Acanthopleurus Agassiz (1842, 1844): A. serratus Agassiz $(1842,1844)$ and A. collettei Tyler (1980), both from the Oligocene of Canton Glarus, Switzerland. The first dorsal spine is far larger than the second spine (only two spines are shown and described but the three or four smaller more posterior ones probably were not as well preserved or observable), the left and right pelvic spines are also prominent and there is a long and probably shaft-like posterior process of the pelvis between them, the caudal peduncle tapers posteriorly, and the spiny dorsal-fin base is much shorter than the soft dorsal-fin base, all typical features of triacanthids. As with Acanthopleurus, most of the internal osteological features are poorly exposed, but all features evident in the illustration of Cephalacanthus trispinosus are consistent with its being referable to Acanthopleurus.

There is no explanation for the listing in the description of Cephalacanthus trispinosus of four pelvic fin elements, 20 caudal fin rays, and 23-24 vertebrae, and the illustration does not clarify the matter; presumedly these meristics are misinterpretations of the difficult to decipher impressions in black shales that are typical of all other specimens of the Oligocene Acanthopleurus.

While the species described by Ciobanu as Cephalacanthus trispinosus is surely a species of Acanthopleurus, it is impossible on the basis of its description and illustration to determine whether it is a valid third species of that genus or a synonym of one of the two presently recognized species. The type specimen will have to be re-examined before that determination can be made. For the moment we simply note that the $29 \mathrm{~mm}$ SL holotype of Acanthopleurus trispinosus has a relatively deep body of $35 \% \mathrm{SL}$, a depth more like that of $A$. collettei than that of the more shallow bodied A. serratus. However, the available specimens of both A. serratus (11 specimens, $78-153 \mathrm{~mm} \mathrm{SL}$ ) and $A$. collettei (7 specimens, $82-120 \mathrm{~mm} \mathrm{SL}$ ) are much larger than that of trispinosus and body depth in triacanthids is greatest in small specimens and decreases with increasing specimen size to such an extent that the small holotype of trispinosus cannot be placed with confidence on extrapolations of the ontogenetic body depth curves given by Tyler (1980:97, fig. 46) for either of the two species of Acanthopleurus.

\section{Conclusion}

The data discussed herein allow us to assign the two new Oligocene genera within each of the two subfamilies of triacanthodids as their first fossil representatives. The data also support the hypothesized sistergroup relationship of one of the fossil taxa (Prohollardia) to a particular Recent genus (Hollardia) of Hollardiinae, and of the other (Carpathospinosus) to a group of several Recent genera of Triacanthodinae characterized by especially broad pelvises. It also establishes that the separation of the two subfamilial lineages of triacanthodids took place no less than about 29 to 24 MYA.

The information in this study makes it obvious that all of the osteological differences between the two subfamilies of triacanthodids and their triacanthid and other outgroups need to be re-analyzed cladistically to expand the data base of polarized characteristics. That will be necessary in interpreting the phylogenetic relationships of the subfamilies beyond the presently recognized differences in the shapes and articulations of the bones in the supraoccipital-epiotic region, the shape of the posterior process of the pelvis, and the shape of the first anal-fin basal pterygiophore. 


\section{Literature Cited}

Agassiz, Louis

1842. Recherches sur les poissons fossiles. Volume 2, plate 75. Neuchâtel.

1844. Recherches sur les poissons fossiles. Volume 2, part 2: pages 73-336. Neuchâtel.

Bannikov, Alexandre F.

1991. On the Systematic Position of the Family Caproidae with Reference to the Eocene Genus Acanthonemus. Journal of Ichthyology (translation of Voprosy Ikhtiologii), 31(5):47-58.

Berg, Leo S.

1940. Classification of Fishes, Both Recent and Fossil. Travaux de l'Institut Zoologique de l'Academie des Sciences de l'USSR, 5:87-517.

Ciobanu, Mihai

1977. Fauna fosila din Oligocenul de la Piatra Neamt. 159 pages. Bucuresti: Editura Academiei Republicii Socialiste Romania.

Gaudant, Mireille

1977. Sur la découverte dans le Crétacé de Laveiras (Portugal) du plus ancien zeiforme connu. Geobios, 10(3):487-488.

1978. Contribution à l'étude anatomique et systématique de l'ichthyofaune cénomanienne du Portugal, Première partie: les "Acanthopterygiens." Comunicações dos Serviços Geológicos de Portugal, 63:105-149.

Gayet, Mireille

1980a. Sur la découverte dans la Crétacé de Hadjula (Liban) du plus ancien Caproidae connu. Comptes Rendus de l'Académie de Sciences (Paris), series D, 290:447-448.

1980b. Découverte dans le Crétacé de Hadjula (Liban) du plus ancien Caproidae connu. -Etude anatomique et phylogenetique. Bulletin $d u$ Muséum National d'Histoire Naturelle (Paris), series 4, section C, 2(3):259-269.

Gregory, William K.

1933. Fish Skulls: A Study of the Evolution of Natural Mechanisms. Transactions of the American Philosophical Society, 23(2):1-481.

Heemstra, Phillip C.

1980. A Revision of the Zeid Fishes (Zeiformes: Zeidae) of South Africa. Ichthyological Bulletin of the Institute of Ichthyology, Rhodes University, Grahamstown, 41:1-18.

Jerzmańska, Anna

1968. Ichthyofaune des couches a ménilite (flysch des Karpathes). Acta Palaeontologica Polonica, 13(3):379-488.

1974. Kotlarczykia bathybia gen. n., sp. n. (Teleostei) from the Oligocene of the Carpathians. Acta Palaeontologica Polonica, 19(2):281-289.

1979. Oligocene Alepocephaloid Fishes from the Polish Carpathians. Acta Palaeontologica Polonica, 24(1):65-76.

Jerzmańska, Anna, and Janusz Kotlarczyk

1976. The Beginnings of the Sargasso Assemblage in the Tethys? Palaeogeography, Palaeoclimatology, Palaeoecology, 20:297-306.

1981. Fish Fauna Evolutionary Changes as the Basis of the Stratigraphy of the Menilite Beds and Krosno Beds. Zemni Plyn a Nafta, 26(1): 63-74.

Kotlarczyk, Janusz, and Anna Jerzmańska

1976. Biostratigraphy of the Menilite Beds of Skole Unit from the Polish Flysh Carpathians. Bulletin de l'Académie Polonaise des Sciences, Serie des Sciences de la Terre, 24(1):55-61.

1988. Ichtiofauna w stratygrafii Karpat. Przeglad Geologiczny, 6: 346-352.
Norman, John R.

1934. A Systematic Monograph of the Flatfishes (Heterosomata), Volume 1: Psettodidae, Bothidae, Pleuronectidae. 459 pages. London: British Museum (Natural History).

Poey, Felipe

1861. Poissons de Cuba, especes nouvelles, Part 3. Memorias sobre la Historia Natural de la Isla de Cuba, 2:337-356.

Rosen, Donn E.

1984. Zeiforms as Primitive Plectognath Fishes. American Museum Novitates, 2782:1-45.

Shufeldt, Robert W.

1888. Further Studies on Grammicolepis brachiusculus, Poey. Journal of Morphology, 2(2):271-295.

Sorbini, Lorenzo

1979. Segnalazione di un plettognato Cretacico Plectocretacicus nov. gen. Bollettino del Museo Civico di Storia Naturale di Verona, 6:1-4.

1983. La collezione Baja di pesci e piante fossili di Bolca. 117 pages. Verona: Museo Civico di Storia Naturale di Verona.

Sorbini, Lorenzo, and Cristina Bottura

1987. Antigonia veronensis, an Eocene Caproid from Bolca (Italy). Bollettino del Museo Civico di Storia Naturale di Verona, 14:255-269.

Starks, Edwin C.

1898. The Osteology and Relationships of the Family Zeidae. Proceedings of the United States National Museum, 21:469-476.

Świdnicki, Jacek

1986. Oligocene Zeiformes (Teleostei) from the Polish Carpathians. Acta Palaeontologica Polonica, 31(1-2):111-135.

1988. Juveniles of Some Oligocene Antigonia (Caproidae, Teleostei) from the Polish Carpathians. Acta Palaeontologica Polonica, 33(3): 249-259.

Tyler, James C.

1968. A Monograph on Plectognath Fishes of the Superfamily Triacanthoidea. Academy of Natural Sciences of Philadelphia Monograph, $16: 1-364$.

1973. A New Species of Triacanthodid Fish (Plectognathi) from the Eocene of Monte Bolca, Italy, Representing a New Subfamily Ancestral to the Triodontidae and to the Other Gymnodonts. Museo Civico di Storia Naturale di Verona, Studi e Ricerche sui Giacimenti Terziari di Bolca, 2:128-156.

1980. Osteology, Phylogeny, and Higher Classification of the Fishes of the Order Plectognathi (Tetraodontiformes). National Oceanic and Atmospheric Administration Technical Report, National Marine Fisheries Senice Circular, 434:1-422.

Tyler, James C., and Alexandre F. Bannikov

1992. A Remarkable New Genus of Tetraodontiform Fish with Features of Both Balistids and Ostraciids from the Eocene of Turkmenistan. Smithsonian Contributions to Paleobiology, 72:1-14.

Winterbottom, Richard

1974. The Familial Phylogeny of the Tetraodontiformes (Acanthopterygii: Pisces) as Evidenced by Their Comparative Myology. Smithsonian Contributions to Zoology, 155:1-201.

Zehren, Steven J.

1987. Osteology and Evolutionary Relationships of the Boarfish Genus Antigonia (Teleostei: Caproidae). Copeia, 1987(3):564-592. 



\section{REQUIREMENTS FOR SMITHSONIAN SEAIES PUBLICATION}

Manuscripts intended for series publication receive substantive review (conducted by their originating Smithsonian museums or offices) and are submitted to the Smithsonian Institution Press with Form S1-36, which must show the approval of the appropriate authority designated by the sponsoring organizational unit. Requests for special treatment-use of color, foldouts, case-bound covers, etc.-require, on the same form, the added approval of the sponsoring authority.

Review of manuscripts and art by the Press for requirements of series format and style, completeness and clarity of copy, and arrangement of all material, as outlined below, will govern, within the judgment of the Press, acceptance or rejection of manuscripts and art.

Copy must be prepared on typewriter or word processor, double-spaced, on one side of standard white bond paper (not erasable), with $11 / 4^{\prime \prime}$ margins, submitted as ribbon copy (not carbon or xerox), in loose sheets (not stapled or bound), and accompanied by original art. Minimum acceptable length is 30 pages.

Front matter (preceding the text) should include: title page with only title and author and no other information; abstract page with author, title, series, etc., following the established format; table of contents with indents reflecting the hierarchy of heads in the paper; also, foreword and/or preface, if appropriate.

First page of text should carry the title and author at the top of the page; second page should have only the author's name and professional mailing address, to be used as an unnumbered footnote on the first page of printed text.

Center heads of whatever level should be typed with initial caps of major words, with extra space above and below the head, but no other preparation (such as all caps or underline, except for the underline necessary for generic and specific epithets). Run-in paragraph heads should use period/dashes or colons as necessary.

Tabulations within text (lists of data, often in parallel columns) can be typed on the text page where they occur, but they should not contain rules or numbered table captions.

Formal tables (numbered, with captions, boxheads, stubs, rules) should be submitted as carefully typed, double-spaced copy separate from the text; they will be typeset unless otherwise requested. If camera-copy use is anticipated, do not draw nules on manuscript copy.

Taxonomic keys in natural history papers should use the aligned-couptet form for zoology and may use the multi-level indent form for botany, if cross referencing is required between key and text, do not include page references within the key, but number the keyed-out taxa, using the same numbers with their corresponding heads in the text.

Synonymy in zoology must use the short form (taxon, author, year:page), with full reference at the end of the paper under "Literature Cited." For botany, the long form (taxon, author, abbreviated journal or book title, volume, page, year, with no reference in "Literature Cited") is optional.

Text-reference system (author, year:page used within the text, with full citation in "Literature Cited" at the end of the text) must be used in place of bibliographic footnotes in all Contribustions Series and is strongly recommended in the Studies Series: "(Jones, 1910:122)" or "...Jones (1910:122)." If bibliographic footnotes are required, use the short form (author, brief title, page) with the full citation in the bibliography.

Footnotes, when few in number, whether annotative or bibliographic, should be typed on separate sheets and inserted immediately after the text pages on which the references occur. Extensive notes must be gathered together and placed at the end of the text in a notes section.

Bibliography, depending upon use, is termed "Literature Cited," "References," or "Bibliography." Spell out titles of books, articles, journals, and monographic series. For book and article titles use sentence-style capitalization according to the rules of the language employed (exception: capitalize all major words in English). For journal and series titles, capitalize the initial word and all subsequent words except articles, conjunctions, and prepositions. Transliterate languages that use a non-Roman alphabet according to the Library of Congress system. Underline (for italics) titles of journals and series and titles of books that are not part of a series. Use the parentheses/colon system for volume (number):pagination: "10(2):5-9." For alignment and arrangement of elements, follow the format of recent publications in the series for which the manuscript is intended. Guidelines for preparing bibliography may be secured from Series Section, SI Press.

Legends for illustrations must be submitted at the end of the manuscript, with as many legends typed, double-spaced, to a page as convenient.

Illustrations must be submitted as original art (not copies) accompanying, but separate from, the manuscript. Guidelines for preparing art may be secured from the Series Section, SI Press. All types of illustrations (photographs, line drawings, maps, etc.) may be intermixed throughout the printed text. They should be termed Figures and should be numbered consecutively as they will appear in the monograph. If several illustrations are treated as components of a single composite figure, they should be designated by lowercase italic letters on the illustration; also, in the legend and in text references the italic letters (underlined in copy) should be used: "Figure 9b." Illustrations that are intended to follow the printed text may be termed Plates, and any components should be similarly lettered and referenced: "Plate 9b." Keys to any symbols within an illustation should appear on the art rather than in the legend.

Some points of style: Do not use periods after such abbreviations as "mm, ft, USNM, NNE." Spell out numbers "one" through "nine" in expository text, but use digits in all other cases if possible. Use of the metric system of measurement is preferable; where use of the English system is unavoidable, supply metric equivalents in parentheses. Use the decimal system for precise measurements and relationships, common fractions for approximations. Use day/month/ year sequence for dates: "9 April 1976." For months in tabular listings or data sections, use three-letter abbreviations with no periods: "Jan, Mar, Jun," etc. Omit space between initials of a personal name: "J.B. Jones."

Arrange and paginate sequentially every sheet of manuscript in the following order: (1) title page, (2) abstract, (3) contents, (4) foreword and/or preface, (5) text, (6) appendices, (7) notes section, (8) glossary, (9) bibliography, (10) legends, (11) tables. Index copy may be submitted at page proof stage, but plans for an index should be indicated when the manuscript is submitted. 


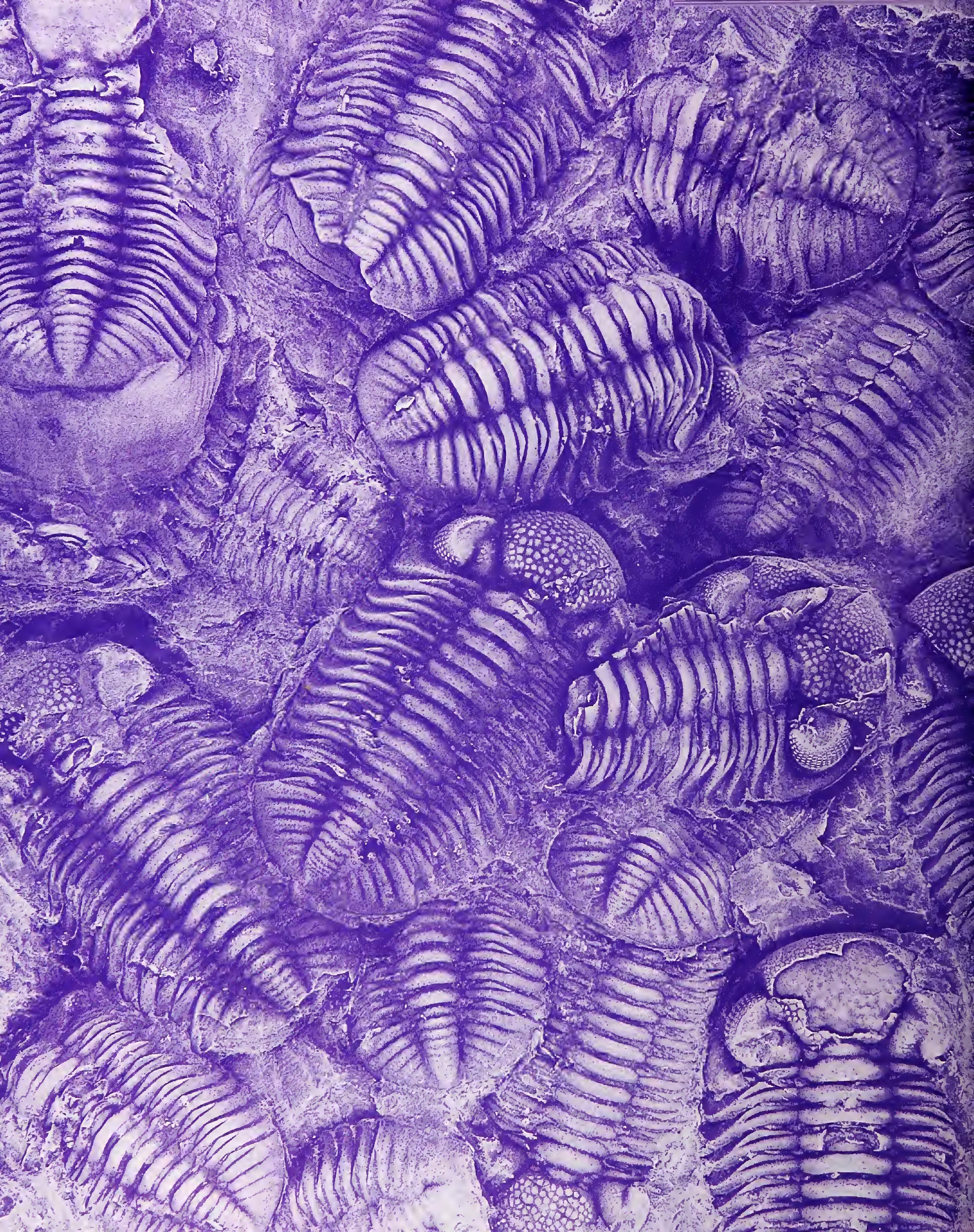

